\title{
GLYCOGEN PHOSPHORYLASE: A MULTIFACETED ENZYME
}

\author{
Presented as the 9th Linderstrøm-Lang Award Lecture at the Carlsberg Laboratory \\ Copenhagen on 29th November, 1989
}

by

LOUISE N. JOHNSON

Laboratory of Molecular Biophysics, Rex Richards Building,

South Parks Road, Oxford OXI 3QU, UK

\begin{abstract}
Keywords: Glycogen phosphorylase, time resolved studies, catalytic mechanism, oligosaccharide recognition, allosteric mechanism, phosphorylation, stereoelectronic effects
\end{abstract}

\section{INTRODUCTION}

It is a very great honour for me to receive the Linderstrøm-Lang award and to join your list of distinguished previous recipients. The work of the Carlsberg Laboratory first came to my notice in the mid 1960s when I joined Professor F.M. RichaRds's Laboratory at Yale for a post doctoral year. There I learnt of the influence and inspiration of LINDERSTRøM.LANG and the pioneering work that had been achieved on protein folding. In one of the earliest and most remarkable experiments on molecular recognition it was shown that specific cleavage by subtilisin of the peptide bond between residues 19 and 20 in ribonuclease yielded ribonuclease $S$ protein and peptide; separately neither was catalytically active but on association full activity was regained. Now, the Laboratory is distinguished in many spheres but especially so in the study of enzymes involved in carbohydrate metabolism and it is this area that makes a link with the theme of my lecture, glycogen phosphorylase. The discussion of our recent results on the $\mathrm{X}$-ray crystallography of this enzyme will centre around the properties associated with protein carbohydrate recognition, the mechanism of catalysis with special reference to time resolved
$\mathrm{X}$-ray crystallographic work, and the allosteric mechanism.

\section{Glycogen phosphorylase}

Glycogen phosphorylase (EC 2.4.1.1) catalyses the degradative phosphorylation of glycogen to glucose-1-phosphate, the initial step in the generation of metabolic energy in muscle.

$(\text { Glycogen })_{n}+P_{i}<=>(\text { Glycogen })_{n-1}+$ $\alpha$-D-Glucose-1-phosphate

This large enzyme (subunit molecular weight 97,440 ; functionally active form dimer) is an archetypal control enzyme. It exhibits regulation both by reversible phosphorylation and by allosteric effectors and is able to integrate diverse signals associated with ligand binding at 5 spatially distinct sites. To a first approximation these effects can be understood in terms of an equilibrium between several conformational states ranging from a low affinity $T$ state to a high affinity $R$ state according to the model of MoNOD et al. (58) (Fig. 1). In resting muscle, phosphorylase is in the $b$ form $T$ state and requires AMP for activation to the $\mathrm{R}$ state $(12,30)$. The enzyme is inhibited by the $T$ state ligands, glucose-6-P. ATP and ADP and the R state ligand UDPG. 


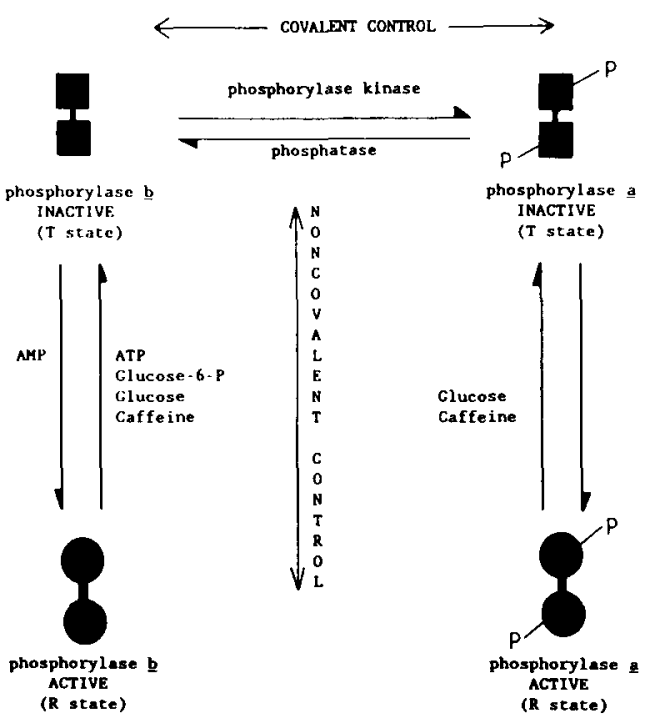

Figure 1. Schematic representation of the allosteric and covalent activation mechanism of glycogen phosphorylase. $T$ and $R$ subunits are shown as squares and circles, respectively (from MarTiN, 1990).

In response to nervous or hormonal signals the enzyme is converted to phosphorylase $a$ through phosphorylation of a single serine, Ser14, catalysed by phosphorylase kinase (45). Phosphorylase $a$ is active in the absence of AMP although the activity may be augmented $(\sim 10 \%)$ by AMP (47). At high concentrations adenine nucleotides and other aromatic compounds derived from purines (e.g. caffeine) bind at an additional site and inhibit activity by restricting access to the catalytic site and by stabilisation of the T state conformation (40). In both phosphorylase $a$ and phosphorylase $b$ this inhibition is synergistic with glucose binding at the catalytic site (41). Glycogen itself is also an effector of phosphorylase. Glycogen promotes dissociation from low activity $R$ state tetramers to active $\mathbf{R}$ state dimers through binding at a high affinity surface site that is distinct from the catalytic site $(39,55,65)$. In vivo this site functions to secure the enzyme to the glycogen particle $(56,75)$. Phosphorylase contains an essential cofactor, pyridoxal phosphate (4), which is bound via a Schiff base to Lys680 in the amino acid sequence (72). The 5'-phosphate group plays an obligatory role in catalysis (63) and its state of ionisation is sensitive to the state of acti- vation of the enzyme (17). The properties of the enzyme have been the subject of several reviews $(18,20,35,47,60,62)$.

The crystal structures of all 4 forms of the enzyme shown in Figure 1 have now been solved. The structure of T state phosphorylase $b$ in the presence of the weak activator IMP (7) has been solved at $1.9 \AA$ resolution (1) and the structure of $\mathrm{T}$ state phosphorylase $a$, in the presence of the inhibitor glucose, at $2.1 \AA$ resolution (70). A comparison (71) of the refined high resolution $T$ state structures of phosphorylase $b$ and phosphorylase $a$ showed the conformational changes associated with phosphorylation of Ser14. Both structures were constrained in the $\mathrm{T}$ state conformation and no information was available on the full allosteric response. The crystal structure of R state phosphorylase $b$ in the presence of the activator sulphate has been determined at $2.9 \AA$ resolution and a comparison of $\mathrm{T}$ and $\mathrm{R}$ state structures of phosphorylase $b$ has provided a structural explanation for the cooperative behaviour of ligand binding and allosteric regulation (5). Sulphate is an allosteric effector of phosphorylase $b(15,46,69)$. In the crystal sulphate mimics phosphate and binds at the catalytic site, the AMP allosteric effector site and the Ser-P site. Support for the proposal that crystallisation in the presence of a high concentration of sulphate favours the $\mathbf{R}$ state conformation has come from the results on the crystal structure of phosphorylase $a$ in the presence of ammonium sulphate (6).

The physiologically active form of the enzyme is a dimer (subunit molecular weight 97,000: 842 amino acids). The binding sites for the different ligands are shown in Figure 2.

\section{Protein oligosaccharide recognition}

The discovery that glycogen phosphorylase is tightly bound to glycogen particles but is able to be catalytically active and controlled (56) provided a puzzle that was solved by the demonstration of a second glycogen binding site distinct from the catalytic site $(39,76)$. Preincubation of glycogen phosphorylase with glycogen enhances activity and promotes dissociation of less active tetramers to active dimers $(55,74)$. The dissociation constant for oligosaccharide binding to the storage site ( $\mathrm{K}_{\mathrm{d}}$ approx. $1 \mathrm{~mm}$ ) is 20 fold less than 


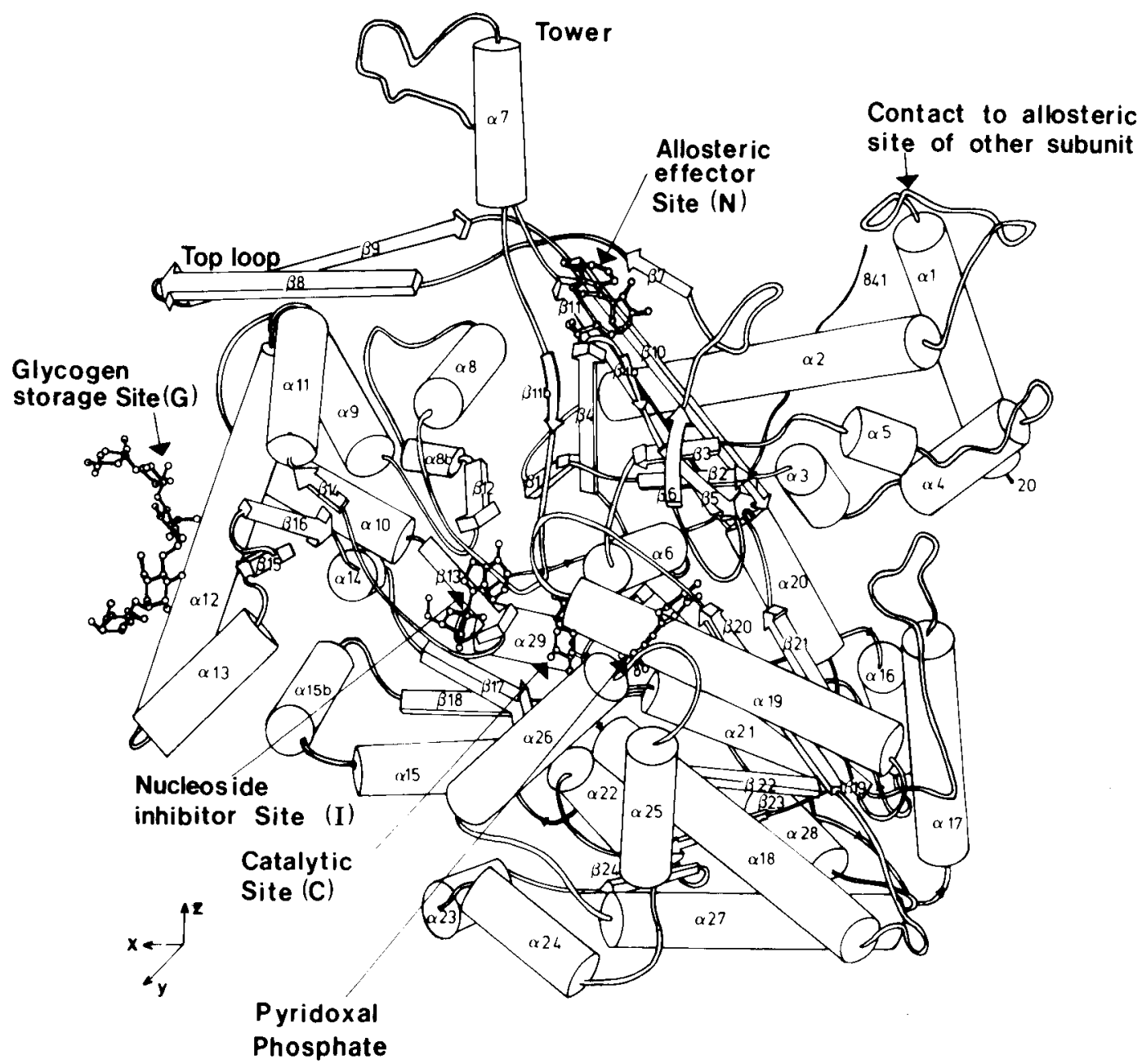

Figure 2. A schematic ribbon diagram of T state phosphorylase $b$ subunit. $\alpha$ helices are shown as cylinders and $\beta$ strands as arrows. The essential cofactor, pyridoxal phosphate, is buried at the centre of the subunit. The catalytic site (C), shown here with glucose-1-phosphate, is close to the cofactor and accessible to the bulk solvent through a channel some $15 \AA$ long. The allosteric effector site $(\mathrm{N})$ is located at the subunit-subunit interface. The glycogen storage site $(G)$ is on the surface of the enzyme and removed from the allosteric and catalytic sites. The nucleoside site (I) is situated at the entrance to the catalytic site channel. This site binds purines or nucleosides or nucleotides at high concentrations and occupancy of this site stabilises the T state and inhibits the enzyme.

the $\mathrm{K}_{\mathrm{m}}$ for oligosaccharide at the catalytic site (39). Studies on the association of oligosaccharides with phosphorylase provide a detailed example of protein sugar interactions.

The glycogen storage site is situated on the surface of the molecule and is over $30 \AA$ from the catalytic and allosteric sites (Fig. 2). A major and a minor glycogen storage site have been defined from the study of the phosphorylasemaltoheptaose complex which has been refined at $2.5 \AA$ resolution to a crystallographic $\mathrm{R}$ factor of $0.146(34,53)$ and from ligand bound complex in which oligosaccharide was present (36). At the major site, binding of only 5 sugars in subsites labelled S3-S4-S5-S6-S7 is observed. The reducing end of the oligosaccharide is in subsite S3 and this site has the lowest crystallographic $\mathrm{z}$ coordinate. Glucosyl residues in these sites make interactions to residues of the $\alpha 12$ helix and the spur formed by the small antiparallel sheet $\beta 15-\beta 16$ (Fig. 2). All the contacts to the oligosaccharide are included in the stretch 
of chain from residues $398-437$ ( $\alpha 12-\alpha 13-\beta 15$ $\beta 16)$. The minor site consists of only 2 sugars and it lies above the non-reducing end of the major site making contacts to the top of the $\alpha 12$ helix, the loop of antiparallel $\beta$ sheet from $\beta 8$ $\beta 9$ (the top loop) and the one contact to a residue from $\alpha$.

The $5 \alpha(1-4)$ linked glucosyl sugars adopt a left-handed amylose like helix such that the 2 ends of the helix curl away from the protein surface. The major conformational changes in the protein involve residues Glu433 and Lys 437 which move so as to optimise contacts with the sugars in subsites S4 and S5. Tyr404 is in the right orientation to make contact with the oligosaccharide.

The contacts between the oligosaccharide and protein are shown in Figure 3. The sugar in S5 makes the largest number of contacts to the

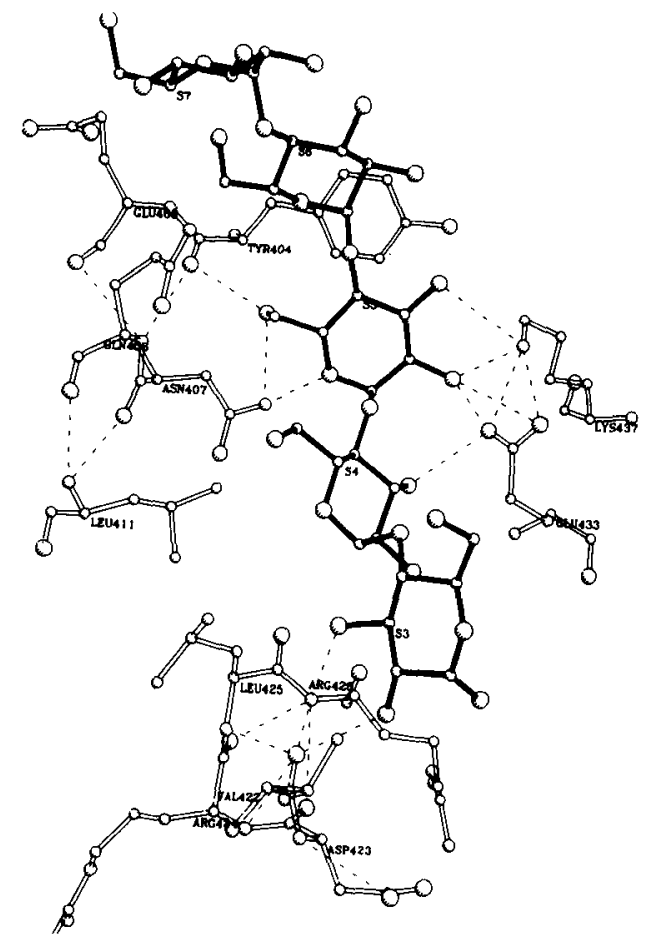

Figure 3. The interactions between maltoheptaose and phosphorylase $b$ at the major glycogen storage site. Only 5 subsites labeled S3-S7 are localised (36). protein and is almost inaccessible to solvent. The $\mathrm{O} 2$ hydroxyl is hydrogen bonded to Glu433 and Lys437, the O5 to Asn407 and the O6 to Tyr404 main chain oxygen and Asn 407 side chain. In addition, there are van der Waals contacts to Tyr404, Asn407, Gln408, Glu433 and Lys437. Tyr404 fits into the groove formed by the glycosidic linkage between subsites S5 and S6 with the lone pair of electrons on the glycosidic oxygen and the ring oxygen directed away from the tyrosine. The hydrogens bonded to $\mathrm{C} 1$ and $\mathrm{C} 2$ atoms of the sugar in site S6 and to the $\mathrm{C} 4$ atom of the sugar in site S5 are directed towards the aromatic ring. Protein-oligosaccharide interactions require complementarity both for the polar and for the non-polar components of the sugars. The stacking of some of the non-polar groups against the oligosaccharide are shown in Figure 4. Five non-polar side chains are involved in this surface site and appear to contribute significantly to the binding energy, although the glycogen storage site itself is not significantly more non-polar than other surface regions of the protein (53).

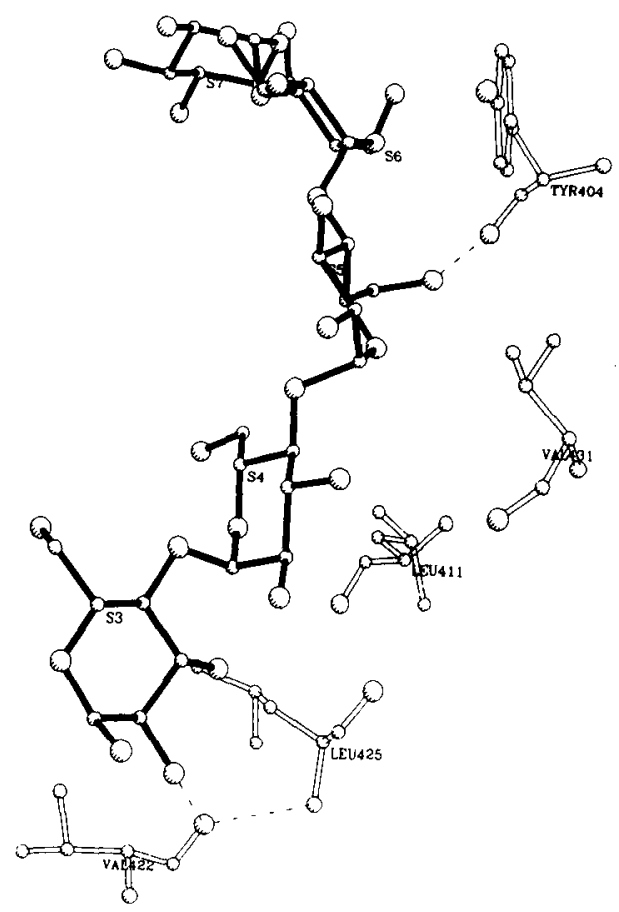

Figure 4. The non-polar residues that contribute to maltoheptaose recognition site (36). 
The specificity of the glycogen storage site for different length oligosaccharides ranging from maltose to maltoheptaose and for other compounds such as acarbose has been discussed (34). Glucose at $100 \mathrm{~mm}$ concentration does not bind to the glycogen storage site in the crystal. Maltose, the smallest compound that has been observed to bind at this site, is located in subsites $\mathrm{S} 4$ and $\mathrm{S} 5$ and the conformation in these subsites is similar to that shown in Figure 3. The sugar bound in subsite 55 makes numerous specific contacts ( 6 hydrogen bonds and 28 van der Waals interactions) and the preference of maltose for this site is not surprising. The preference for S4-S5 rather than S5-S6 is interesting. The sugars in subsites $\$ 4$ and $\$ 6$ make 7 and 16 van den Waals interactions, respectively, but the sugar in subsite $\mathrm{S} 4$ makes one extra hydrogen bond. The hydrogen bonds with Glu433 and Lys437, which span subsites S4 and S5, appear an important determinant of specificity in directing the second sugar of maltose into subsite $\mathrm{S} 4$ despite the fewer van den Waals contacts of this site compared with S6.

\section{Catalysis in the crystal}

Early kinetic and crystallographic experiments had established that glycogen phosphorylase $b$ crystals were catalytically active. The kinetic studies (38) showed a decrease in rate of about 30 fold in the crystal compared with solution but little change in $K_{m}$ values for the substrates, oligosaccharide and glucose-1-P. The studies also showed a large value for $\mathrm{K}_{\mathrm{m}}$ for oligosaccharide (about $175 \mathrm{~mm}$ ), which was similar for the enzyme in the crystal and in solution. $\mathrm{X}$-ray experiments on catalysis in the crystal showed that the reaction could be followed either in the direction of oligosaccharide breakdown with the formation of glucose-1-P or in the direction of oligosaccharide synthesis with the liberation of inorganic phosphate (23). In these experiments oligosaccharide was not observed to bind at the catalytic site although it must have visited the catalytic site in order to achieve the catalysis. In the T state access to the catalytic site is restricted by a loop the 280 s loop (residues 281 to 287 ) and this observation provides an explana- tion for the low affinity of the enzyme for oligosaccharide (Fig. 2). Our most informative studies on catalysis in the crystal have been carried out with the small pseudo substrate heptenitol.

The use of glycosylic substrates to probe carbohydrase enzyme mechanisms have been pioneered by HEHRE and LEHMANN and their colleagues (25). Glycosylic substrates are compounds of nonglycosidic structure with the potential anomeric carbon atom linked via an electron rich bond. In the presence of inorganic phosphate, glycogen phosphorylase catalyses the non-reversible phosphorylation of heptenitol to the product heptulose-2-phosphate ( $\beta$-1-C-methyl, $\alpha$-D-glucose-1-phosphate) (42, 43) (Fig. 5). Heptulose-2-phosphate (H2P) is a potent inhibitor of the enzyme with a $\mathrm{K}_{\mathrm{i}}=14 \mu \mathrm{M}$. The product is bound with a considerably higher affinity than the closely related substrate (or product) glucose 1-P where $\mathrm{K}_{\mathrm{m}}$ is about $3 \mathrm{~mm}$. In crystallographic experiments (54) where heptulose-2phosphate was formed in situ in the crystal, a direct interaction between the cofactor phosphate and the product phosphate was observed and an explanation put forward for the tight binding of heptulose-2-phosphate compared with glucose 1-P. Both the kinetic and struc-

(a)

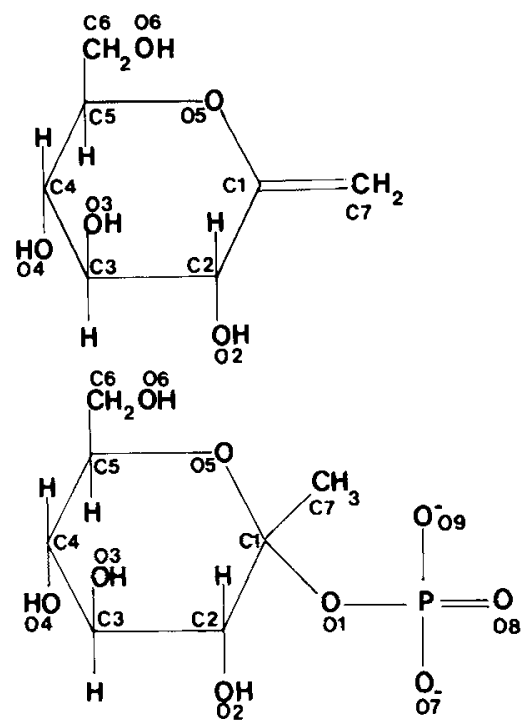

Figure 5. The structures of heptanitol and heptulose2-phosphate and the numbering system for the atoms (36). 

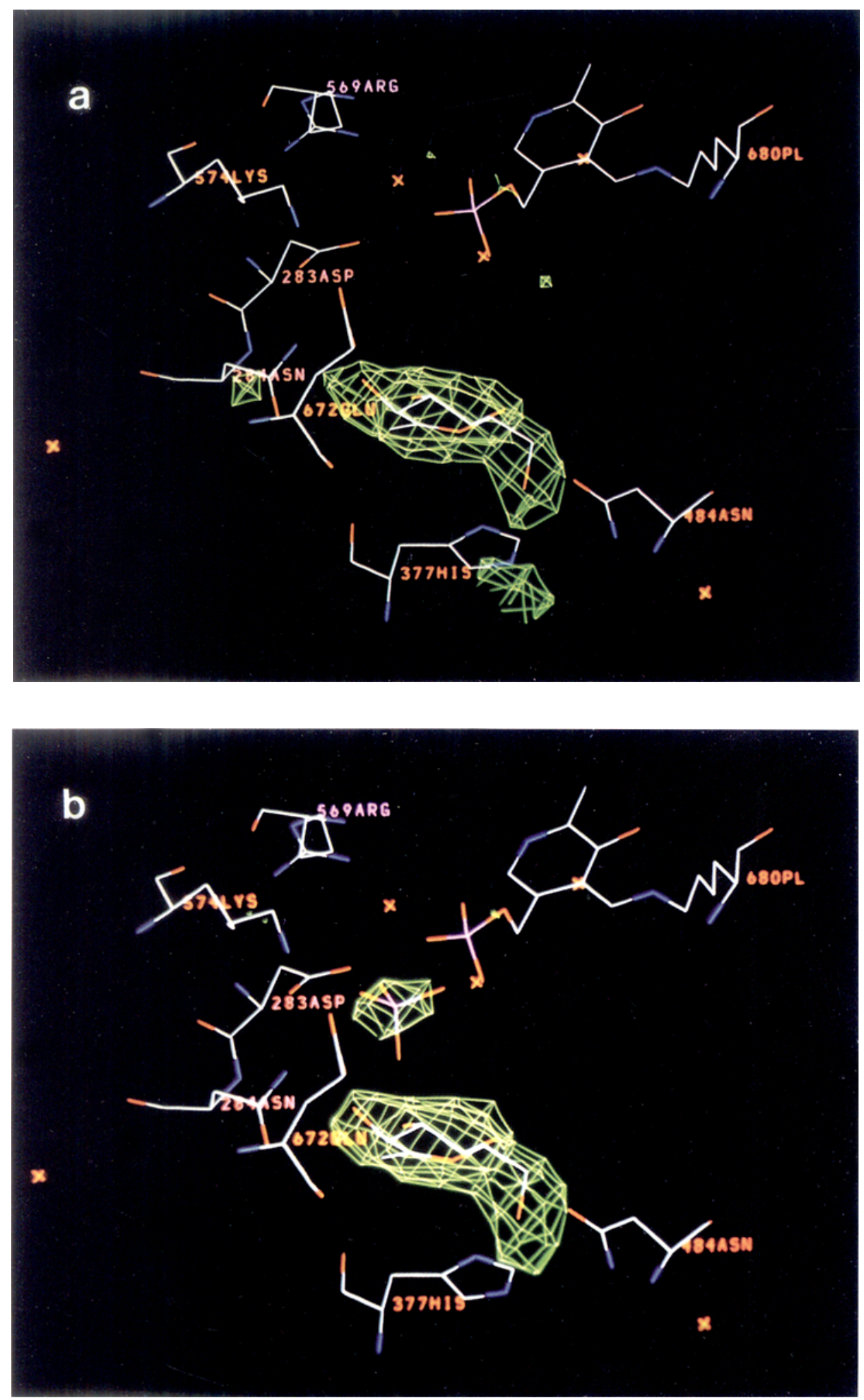


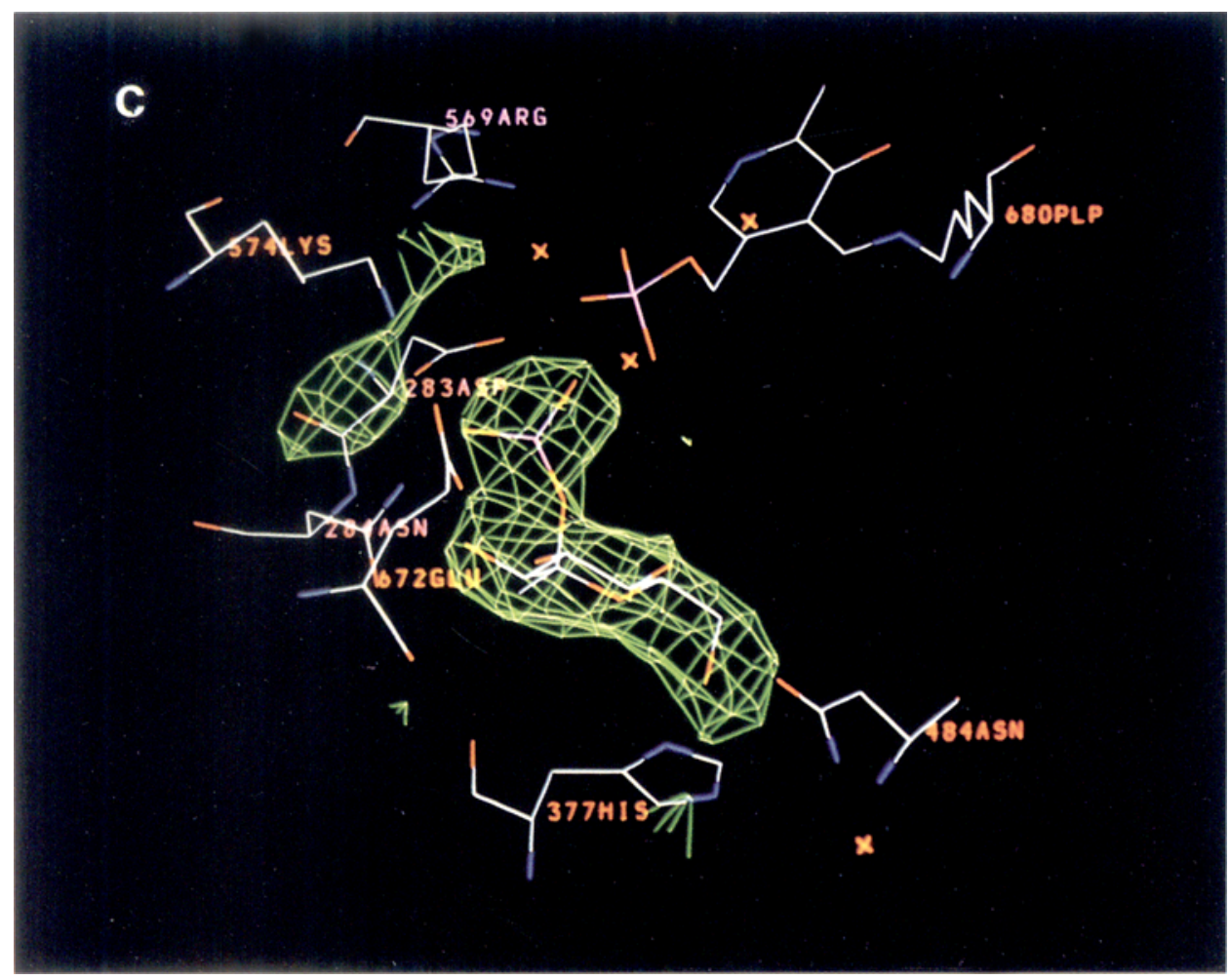

Figure 6. Difference Fourier syntheses in the vicinity of the catalytic site of glycogen phosphorylase $b$ for the heptenitol to heptulose-2-phosphate conversion. A single positive contour is shown (300 arbitrary units). Selected amino acids and the pyridoxal phosphate in the native enzyme conformation are shown. Water molecules are indicated as crosses. (a) The control experiment: crystal soaked in $100 \mathrm{~mm}$ heptenitol. The glucopyranose ring is viewed almost edge on. His 377 is displaced slightly as indicated by additional positive contours. (b) Early stage of the reaction $100 \mathrm{~mm}$ phosphate, $50 \mathrm{~mm}$ phosphate, $2.5 \mathrm{~mm}$ AMP; $10 \mathrm{~min}$ soak; $1 \mathrm{~h}$ data collection at $13^{\circ} \mathrm{C}$. Additional electron density for the phosphate is apparent. (c) Reaction completed: $100 \mathrm{~mm}$ heptenitol, 50 mм phosphate, 2.5 mM AMP, $50 \mathrm{~mm}$ maltoheptaose; $50 \mathrm{~h}$ soak; $2.5 \mathrm{~h}$ data collection. The product heptulose-2-phosphate is apparent from the electron density and there are additional indications for the movement of Arg569 (23).

tural results showed that heptulose-2-phosphate exhibited some properties characteristic of a transition state analogue.

It is difficult to obtain a value for the turnover number of the enzyme with heptenitol because of strong product inhibition. However, arsenolysis of heptenitol (a reaction that is closely similar to phosphorylysis but which yields a product that decomposes and which does not inhibit the enzyme) can be followed and gives a turnover of about $18 \mathrm{~min}^{-1}$ (43). This compares with a value of about $100 \mathrm{sec}^{-1}$ for the natural reaction with glycogen. In the crystal the reaction will be slower. KASVINSKY and MADSEN (38) have demonstrated that the reaction is approximately 30 fold slower in the crystal than in solution. In the time resolved experiments the control properties of the enzyme were exploited to further slow down the reaction so that neither AMP or oligosaccharide were effective activators. Under these conditions the reaction rate may be reduced by as much as 9000 fold leading to a turnover of about $15 \%$ in an experiment with a time course of 70 $\min (23)$.

The time resolved experiments at the Synchrotron Radiation Source, Daresbury involved strenuous X-ray data collection achievable with superb group work. In the experiments the crystal was mounted in a flow cell $(22,78)$ and the reaction initiated by flowing substrate over the 
crystal. Diffusion and binding times were measured in separate experiments (33) and were found to take 10 to $20 \mathrm{~min}$ depending on the size of ligand and crystal size. X-ray data were collected to $2.5 \AA$ resolution on an Arndt-Wonacott oscillation camera (3) at the synchrotron stations $(27,28)$ either immediately or after various resting times which allowed the reaction to proceed. The results of the experiment with heptenitol are shown in Figure 6. In Figure 6a, the control experiments, heptenitol is shown bound at the catalytic site close to the essential cofactor pyridoxal phosphate. In the time resolved experiment (Fig. 6b) where measurements were completed within 60 min for a crystal soaked in 100 $\mathrm{mm}$ heptenitol, $50 \mathrm{~mm}$ phosphate and $2.5 \mathrm{~mm}$ AMP for $10 \mathrm{~min}$ the difference electron density map showed the addition of a phosphate group. A series of other experiments with different time intervals and conditions were carried out (23) but only the end result (54) is shown in Figure $6 \mathrm{c}$. The product heptulose-2-phosphate has been formed and there is a direct interaction with the product phosphate and the cofactor phosphate.

\section{The phosphorylase-product complex}

The crystal structure of the phosphorylaseheptulose-2-phosphate (36) complex has been refined at $2.9 \AA$ resolution by molecular dynamics and crystallographic least squares procedures (8). The product is firmly bound at the catalytic site and exhibits thermal factors that are comparable to the most well ordered regions of the enzyme. The major conformational change of the enzyme is a movement of an arginine residue, Arg569, from a position buried in the protein to a new position in which it can contact the product phosphate. The importance of this residue for phosphorylase catalysis and control has been previously recognised from chemical modification experiments $(14,73)$. The arginine displaces an acidic group, Asp283, from the catalytic site and this replacement of an acidic group by a basic group is a key feature of the creation of the phosphate recognition site. Three water molecules are displaced from the catalytic site by heptulose-2-phosphate binding, two by the phosphate group and one by the $\mathrm{O} 3$ hydroxyl. The interactions of the pyridoxal phosphate with the enzyme are essentially unchanged from those of the native enzyme (61) apart from the contact to heptulose-2-phosphate.

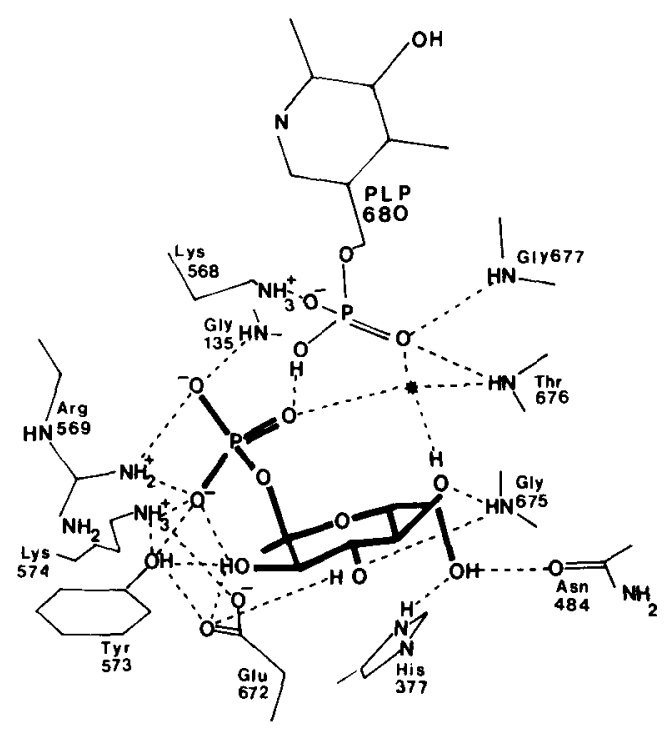

Figure 7. Schematic representation of the polar contacts between heptulose-2-phosphate and phosphorylase $b(36)$.

The interactions between the product and the enzyme are summarised in Figure 7. In common with other oligosaccharide binding proteins, all the polar groups of the sugar are observed to form hydrogen bonds with the enzyme. The exception is the ring oxygen, O5, whose separation from the main chain N of Leu136 (3.5 $\AA)$ is long for a hydrogen bond. Most of the protein groups involved in the hydrogen bonds are from planar groups (main chain N of Gly675 and 677, Asn484, His377, Glu672 and Arg569). The product phosphate is hydrogen bonded to the cofactor phosphate. The position is stabilised by ionic interactions and hydrogen bonds of the product phosphate to Arg569, Lys574, Tyr573 and the main chain $\mathrm{N}$ of Gly135. Contacts between the 2 phosphates are also mediated by a water molecule that bridges the phosphate oxygens and links to the $\mathrm{O} 4$ hydroxyl of the sugar. Gly135 occurs at the start of a helix. The sequence of residues 132 to 137 is Gly-Asn-Gly-Gly-Leu- 
Gly and shows similarity to the Gly-X-Gly-X-XGly sequence that is important in nucleotide phosphate recognition sites (77).

The conformation of heptulose-2-phosphate bound to the enzyme differs from the conformation observed for glucose-1-phosphate (50) in the torsion angle about the glycosidic bond. In the heptulose-2-phosphate complex the torsion angle $\mathrm{O} 5-\mathrm{C} 1-\mathrm{O} 1-\mathrm{P}$ is $224^{\circ}$ and the bond angle at $\mathrm{O} 1$ is $135^{\circ}$. The corresponding values for the glucose-1-phosphate complex are $140^{\circ}$ and $120^{\circ}$. The change in torsion angle appears to be directed by the additional methyl group in the beta configuration and there is an internal hydrogen bond between a phosphate oxygen and the $\mathrm{O} 2$ hydroxyl. The change in torsion angle decreases the product phosphorus-cofactor phosphorus distance from $6.0 \AA$ in the glucose-1-phosphate complex to $4.8 \AA$ in the heptulose-2-phosphate complex and allows the direct hydrogen bond between the phosphates. This is of importance for proposals for the catalytic mechanism.

\section{Catalytic mechanism}

The evidence leading to proposals for the catalytic mechanism and the role of the cofactor 5 , phosphate group have been reviewed $(35,48$,

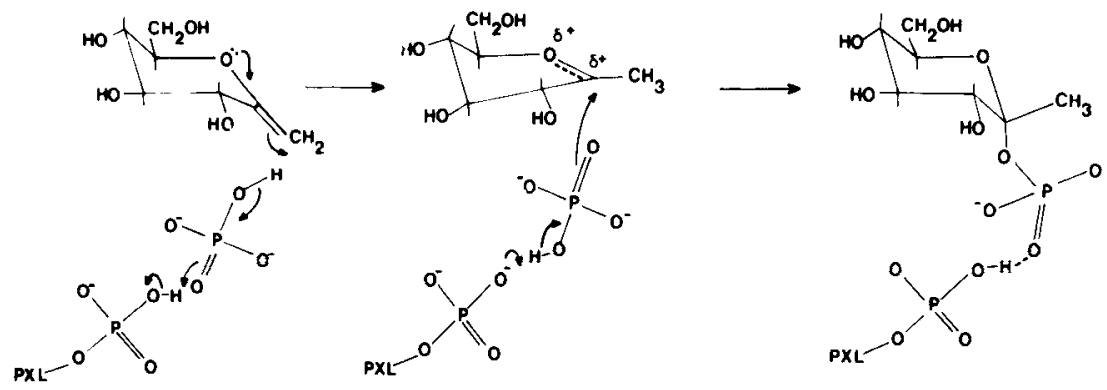

(.)

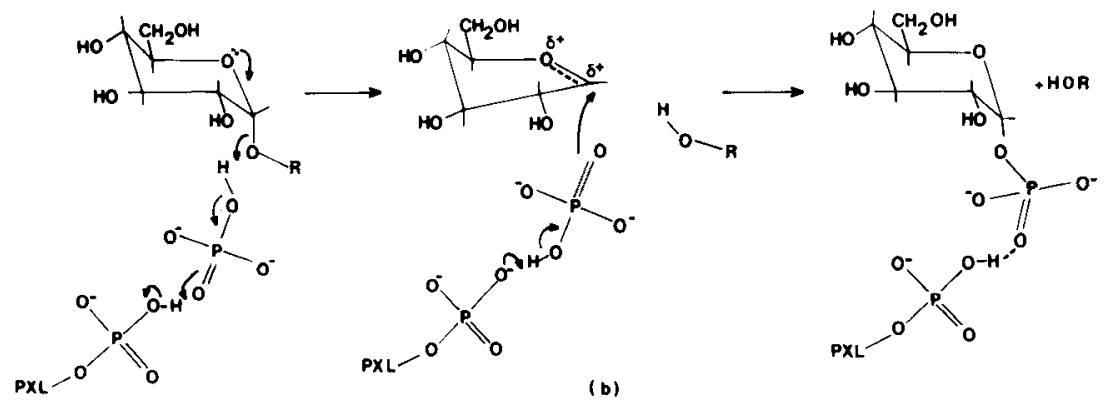

(b)

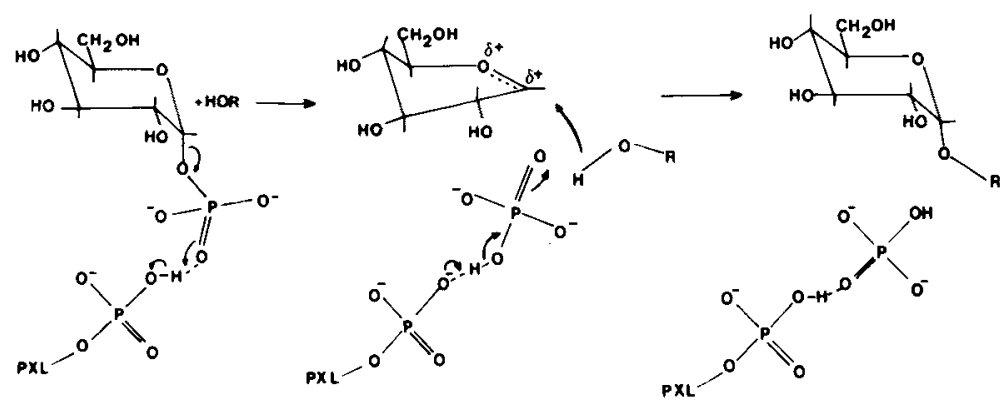

(c)

Figure 8. Proposed catalytic mechanism of phosphorylase for a) phosphorylysis of heptenitol; b) phosphorylysis of oligosaccharides or glycogen; and c) the reverse reaction of oligosaccharide synthesis (36). 
62). The present results support the proposals that have been put forward on the basis of crystallographic (54) and NMR and the kinetic observations $(42,62)$ and demonstrate the additional contribution of stereoelectronic effects. The structures observed favour a mechanism (Fig. 8a) in which phosphorylysis of heptenitol is catalysed by general acid attack of the substrate phosphate promoted by the cofactor phosphate. The proton is donated by the substrate phosphate in a concerted reaction in which the substrate phosphate immediately gains a proton from the cofactor phosphate. After protonation of the methylene carbon, the glucosyl carbonium ion is stabilised by the negatively charged substrate phosphate group. The reaction is completed by the nucleophilic attack of the phosphate group on the carbonium ion to give the product heptulose-2-phosphate. The mechanism can be readily extended to the natural reaction as shown in Figure 8b. In the first step the substrate phosphate protonates the glycosidic oxygen resulting in the cleavage of the $\mathrm{C} 1-\mathrm{O} 1$ bond. The glycosyl carbonium ion is stabilised by the phosphate dianion as before and the reaction completed by attack of the phosphate on the carbonium ion to give glucose-1-phosphate. The crystallographic results show that there are no ionisable groups in the vicinity of the $\mathrm{C} 1$ atom of the glucopyranose ring that could contribute directly to the stabilisation of the transition state carbonium ion nor are there any groups in the vicinity of the $\mathrm{O} 1$ oxygen that could protonate the substrate directly. Indeed the presence of the main chain $\mathrm{N}$ of Leu 136 only $3.5 \AA$ from the ring oxygen is likely to discourage charge delocalisation to an oxonium-carbonium ion in the transition state and provides an explanation as to why classical inhibitors of many glucosidases such as norjirimycin are poor inhibitors of phosphorylase $(2,35)$. The mechanism of phosphorylase is different from glycosidases such as lysozyme in the disposition of groups that promote general acid catalysis and which stabilise the transition state. In lysozyme these functions are performed by two acid groups, a glutamic acid (Glu35) and an aspartate (Asp52). In phosphorylase both these functions are performed by the substrate phosphate promoted by the cofactor phosphate and the catalysis de- pends on the direct interaction of the substrate phosphate and the cofactor phosphate.

In the reverse reaction (Fig. 8c), the cofactor phosphate acts as an acid to protonate the phosphate of glucose-1-phosphate and the C1$\mathrm{O} 1$ bond has to be cleaved without direct protonation of the glycosidic oxygen. The conformation observed for heptulose-2-phosphate is similar to that predicted from stereoelectronic theory to weaken the exo-anomeric effect and promote cleavage of the alpha glycosidic bond (66). The theory predicts that an $\mathrm{O}-\mathrm{C}$ bond in the grouping $\mathrm{O}-\mathrm{C}-\mathrm{O}$ is strongest (i.e. charge delocalisation is greatest) when the lone pair orbital of the oxygen atom is antiperiplanar $\left(180^{\circ}\right)$ to the $\mathrm{C}-\mathrm{O}$ bond of the other oxygen. For $\alpha$-glycosides (Fig. 9a) the unshared pair of electrons on the ring oxygen are properly disposed (i.e. antiperiplanar to the glycosidic bond) to strengthen the $\mathrm{C} 1-\mathrm{O} 5$ bond (endo-anomeric effect) and to contribute to charge delocalisation so as to as-
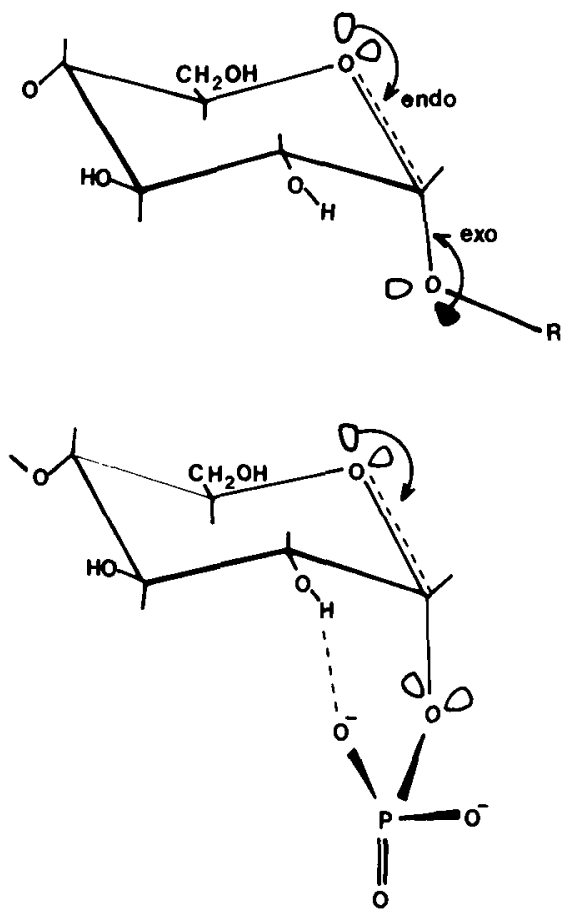

Figure 9. Diagram showing the contribution of stereoelectronic effects for the different conformations of $\alpha$-glycosides. a) Preferred conformation of glucose-1phosphate; both $\mathrm{C1}-\mathrm{O} 5$ (endo) and $\mathrm{C1}-\mathrm{O} 1$ (exo) bonds are stabilised. b) Conformation observed for heptulose2-phosphate; the exo anomeric effect is weakened (36). 
sist the formation of the oxycarbonium ion without distortion of the sugar ring. However, in the preferred conformation of $\alpha$-glycosides, such as that observed for the single crystal structures of such compounds, the torsion angle about $\mathrm{C1}$ $\mathrm{O} 1$ is such that the unshared pair of electrons on the glycosidic oxygen is antiperiplanar to the C1-O5 bond (Fig. 9a). This will tend to strengthen the glycosidic bond (exo anomeric effect), thus making cleavage of this bond more difficult. Rotation about the $\mathrm{C} 1-\mathrm{O} 1$ bond to the position observed in the heptulose-2-phosphate complex weakens the exo-anomeric effect and results in increasing polarisation of the $\mathrm{C} 1-\mathrm{O} 1$ bond (Fig. 9b).

Thus heptulose-2-phosphate formed in the crystal exhibits a conformation that is anticipated to promote cleavage of the glycosidic bond. The presence of the methyl group in $\beta$ configuration prevents access of the oligosaccharide and probably explains why reaction in the direction of glycogen synthesis is not seen with this compound despite its reactive conformation. For glucose-1-phosphate it is anticipated that the presence of oligosaccharide in the catalytic site favours a conformation in which the phosphate is turned from the conformation observed in the binary phosphorylase-glucose-1-phosphate complex towards the cofactor phosphate as observed in the heptulose-2-phosphate complex so that the cofactor phosphate can function as a catalytic group with the assistance of the activated conformation predicted from stereoelectronic theory. The crystallographic results suggest that when the reaction proceeds in the direction of glycogen synthesis the glycosidic bond is weakened by steric factors that facilitate the development of the carbonium ion and ensure that the phosphate is able to act as a base to abstract a hydrogen from the $\mathrm{O} 4$ hydroxyl of the oligosaccharide. When the reaction proceeds in the direction of glycogen degradation the glycosidic bond is weakened by direct protonation. In both directions the substrate phosphate plays a crucial role in transition state stabilisation.

\section{Laue diffraction}

One of the key questions arising from these proposals for the catalytic mechanism concerns the position of the phosphate group in the time resolved experiment (Fig. 6b). Does the peak represent the phosphate in the attacking position as in the ternary enzyme substrate complex or does it represent a small amount of product formed? The separation of the heptulose-2phosphate peak in Figure $6 \mathrm{~b}$ is between 0.4 and $1 \AA$ which is just on the edge of significance for data at $2.9 \AA$ resolution. The question may be answered by recording data at an earlier stage in the reaction. This is made possible by the Laue method.

Laue diffraction refers to the method used by Friedrich, KNIPPING and Von LAUe (19) to record the first X-ray photographs from a crystal of copper sulphate. The method uses the whole polychromatic spectrum of radiation instead of the highly monochromatic beam used in conventional crystallography. The method fell into disuse because $\mathrm{X}$-ray sources did not give a satisfactory white spectrum and because of the difficulties in unravelling the complicated diffraction patterns obtained. The broad spectral range of synchrotron radiation and the high intensity of the beam have been the major factors associated with a revival of this method of recording data $(26,57)$ coupled with the availability of high powered computers and the development of software for indexing and integrating the recorded intensities (29). With the Laue method (white radiation: stationary crystal) a large number of lattice planes diffract simultaneously as the Bragg condition is satisfied for each of these planes by at least one wavelength of the spectrum. Many reflections can thus be recorded in a short time with a single exposure. The first Laue photographs were recorded for phosphorylase in 1984 (Fig. 10). It was found that photographs could be obtained with 1 sec exposures using the broad X-ray spectrum emitted by the wiggler beam line (station 9.7) at the SRS, Daresbury in the wavelength range 0.25 to $2.5 \AA$. Although phosphorylase crystals, like most protein crystals, are sensitive to radiation damage, the crystals grow up to $2 \mathrm{~mm}$ in length so that with a fine $0.2 \mathrm{~mm}$ colimator several exposures can be obtained from a single crystal by translating the crystal after 1 or 2 exposures. This makes it possible to record the native data and to monitor diffusion of ligands and their 


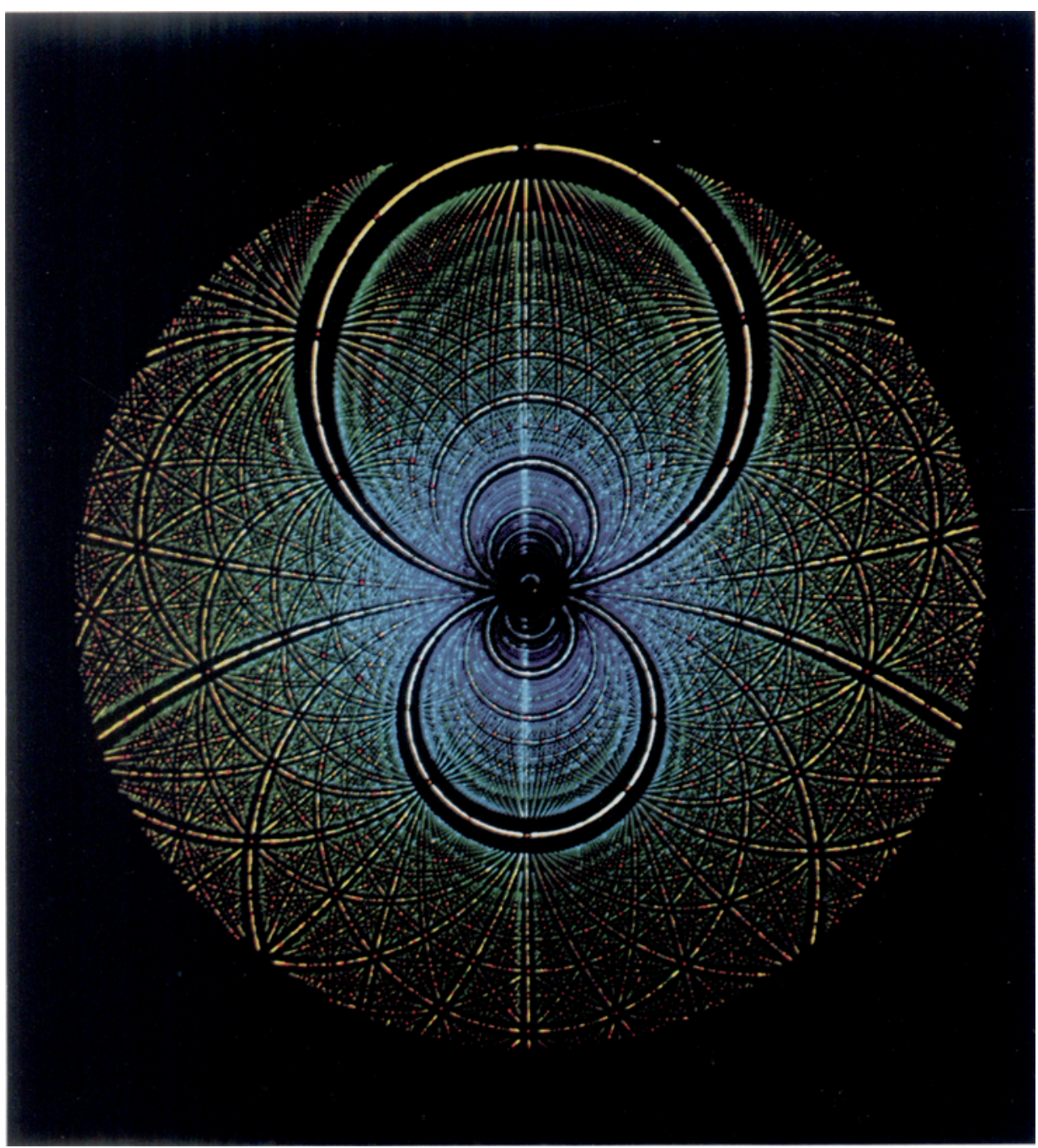

Figure 10. Computer simulated Laue diffraction pattern from a phosphorylase $b$ crystal. Reflections generated by different wavelengths are shown in different colours (blue short wavelength and red long wavelength). A typical Laue photograph of phosphorylase crystals contains about 40,000 spots (23).

binding in a series of time resolved experiments on the second time scale.

In 1987 my colleague Dr. J.HAJDU calculated the first Laue difference map (24) which demonstrated the binding of oligosaccharide to the glycogen storage site of phosphorylase. Recording diffraction data for the native and liganded structures from the same crystal resulted in more precise measurements than when these data are obtained from different crystals. A unique set of
9029 reflections, comprising about a third of the data to $2.5 \AA$ resolution were obtained from 3 photographs each of which had $1 \mathrm{~s}$ exposure. The major loss of data from the films arose not from reflections that exhibited wavelength overlap (which represent only a small fraction of the data (13)) but from reflections that were too close together on the film (i.e. spacing less than $0.2 \mathrm{~mm}$ ) to be resolved. Since that time there have been improvements in data process- 
ing programmes that allow deconvolution of spatially overlapped spots (68). These advances in Laue diffraction methodologies (summarised by HAJDU and JOHNSON (21)) have led to the location of heavy atom binding sites in xylose isomerase (16), the determination of the calcium site in tomato bushy stunt virus (10), the determination of 2 new protein structures by the Laue method (e.g. turkey egg white lysozyme) (P.L.Howell et al., unpublished results) and glyceraldehyde 3-phosphate dehydrogenase from Trypanosoma brucei (F.M.D. VELLIEUx et al., unpublished results) and a study of the active H-ras P21-GTP complex (67).

In the utilisation of the Laue method for time resolved studies on catalysis in the crystal it is essential that the start of the reaction and the start of data collection are synchronised. It is not possible to tolerate start of the reaction by diffusion of ligands over a $10 \mathrm{~min}$ period when the time resolution of data collection is of the order of seconds. Caged compounds $(37,52)$ offer the most promising approach for the synchronisation of reaction and data collection. The substrate is made biologically inert through the attachment of a photolabile protection group, most commonly a nitrophenylester. Subsequent illumination by a laser or a xenon flash lamp results in photodissociation of the protecting group and liberation of the substrate. A scheme for the liberation of phosphate from caged phosphate is shown in Figure 11. In the recent experiments with the H-ras P21 protein a similar chemical blocking group was used to cage GTP; the cagedGTP-P21 protein complex was crystallised and the cage liberated by photolysis to yield an active P21-GTP complex from which data were recorded by the Laue method on a time interval before significant catalysis had occurred (67). For phosphorylase, where very high concentrations of phosphate are required to initiate the reaction, compounds such as those shown in Figure 11 have the disadvantage that the liberated cage, the nitrosoketone group, is highly reactive with the thiols of the protein. In most instances this can be ameliorated by inclusion of a reducing agent such as dithiothreitol but phosphorylase crystals do not tolerate such compounds at high concentrations. Recently, in collaboration with Dr. D.R. Trentham, we have explored the use

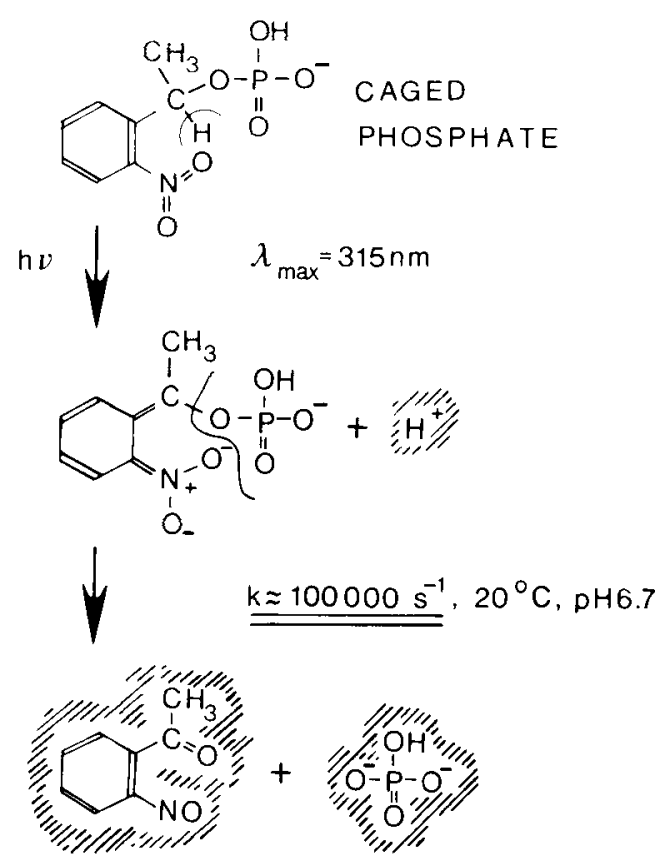

Figure 11. Scheme for the release of phosphate from caged phospate $(21,52)$.

of 3,5-dinitrophenylphosphate with encouraging results. The cage, 3,5-dinitrophenyl can be liberated with high efficiency with 10 flashes from an xenon flash lamp (E. DukE and J.L. MARTIN, unpublished observations). The liberated cage does not react with the protein, and it exhibits a distinct spectral change at $400 \mathrm{~nm}$ so that events in the crystal can be monitored with a specially designed diode array spectrophotometer (J. HaJdu and A. HADFIELD, unpublished results). The way is now open for the crucial time resolved Laue experiment on the phosphorylysis of heptenitol in the phosphorylase crystal.

\section{Allosteric mechanism}

As indicated in the introduction, glycogen phosphorylase is an archetypal control protein that exhibits control both by reversible phosphorylation and by non-covalent association of metabolites. One of the major reasons for the $\mathrm{X}$-ray study of this protein has been to provide a structural explanation for these biological control properties. To a first approximation 
phosphorylase can be understood in terms of the Monod-Wyman-Changeux hypothesis for allosteric proteins (58). The enzyme exists in 2 (or at least 2) interconvertible states, a T state that exhibits low affinity for substrate and effectors and an $\mathrm{R}$ state that exhibits a high affinity (Fig. 1). Our present understanding of the allosteric mechanism, derived from knowledge of the crystal structures of the 4 states of phosphorylase (Fig. 1), rests on the intimate connection between tertiary structure and quaternary structure and the conservation of symmetry as the structure goes from one state to the other. Changes at the Ser-P and AMP sites directly involve subunit contacts so that homotropic and heterotropic interactions between these sites are communicated via conservation of symmetry. The catalytic site is at the centre of the subunit and well removed from the subunit interface. Nevertheless, it is indirectly connected through the 280s loop, the loop of chain that blocks access to the catalytic site in the $T$ state, so that changes in tertiary structure favour a change in quaternary structure (and vice versa) and allow communication between catalytic sites and ailosteric effector sites.

Overall, the tertiary structures of the 4 states of phosphorylase that have been studied crystallographically are very similar. There is a core of residues comprising some $66 \%$ of the structure that differs by less than $0.5 \AA$ between the structures. The major changes in structure take place at the subunit-subunit interface and at the catalytic site. Activation of phosphorylase from the $T$ state to the $R$ state leads to a change in association of the molecule from dimers to tetramers (evidence reviewed by GRAVES and WANG, 1972 (20)). Tetramers exhibit less activity than dimers and under physiological conditions such non-productive association is prevented by the association of the enzyme with glycogen particles. In the $\mathbf{R}$ state structures there are additional changes in surface residues that flank entrance to the catalytic site and are involved in the association of dimers to tetramers. (Details of these changes and their significance for the change in state of aggregation on activation will be described elsewhere). Two subunits of the functional dimer associate at 2 positions located on opposite sides of the enzyme molecule (Fig. 12).
One contact, the cap'/ $\alpha 2$ interface, is formed by the association of the cap' (residues 35'-46') with the $\beta 7$ strand (residues 191 to 193 ) and $\alpha 2$ helix (residues 47-48) of the other subunit. (Residues from the symmetry related molecule are designated with superscript prime). This interface includes the allosteric effector site and Ser$\mathrm{P}$ binding site. An identical interface is produced by the molecular 2 -fold symmetry operation. A second subunit-subunit contact involves the tower interface and consists of the anti-parallel association of 2 symmetry related helices, $\alpha 7$ (residues 262-276). The catalytic site is separated from the allosteric site and Ser-P site by $35 \AA$ and $45 \AA$, respectively, and from the symmetry related catalytic site by $70 \AA$. The Ser-P site is located $15 \AA$ from the allosteric site and symmetry related allosteric and Ser-P sites are separated by $40 \AA$ and $35 \AA$, respectively. Long range interactions therefore operate between different ligand binding sites.

The structures of $\mathrm{R}$ state phosphorylases $a$ and $b$ and $\mathrm{T}$ state phosphorylase $a$ are similar at the allosteric site interface and the vicinity of the Ser-P site. At the tower-tower interface and the catalytic site the two $R$ state structures are very similar and differ from those of the $T$ state structures. T state phosphorylase $a$ therefore exhibits the interesting properties of a $\mathrm{T}$ like structure at the catalytic site (promoted by the binding of the inhibitor glucose) and an $\mathrm{R}$ like structure at the allosteric site (promoted by the Ser-P). The following discussion will focus on the allosteric changes between $T$ state phosphorylase $b$ and $\mathrm{R}$ state phosphorylase $a$, as these allow the most complete description of the conformational response. The structure determination and analysis of the $\mathbf{R}$ state phosphorylase structures has been led by my colleague Dr. D. BARFord $(5,6,32)$.

The quaternary conformational change can be described as a rotation of one subunit relative to the other by $10^{\circ}$ about an axis approximately perpendicular to the molecular 2 -fold axis, positioned close to the cap'/ $\alpha 2$ interface. This draws the subunits together at the cap' $/ \alpha 2$ interface and apart at the tower-tower interface (Figs. 12e and f). The quaternary conformational change is promoted through the concerted but localised conformational change at the cap' $/ \alpha 2$ interface 


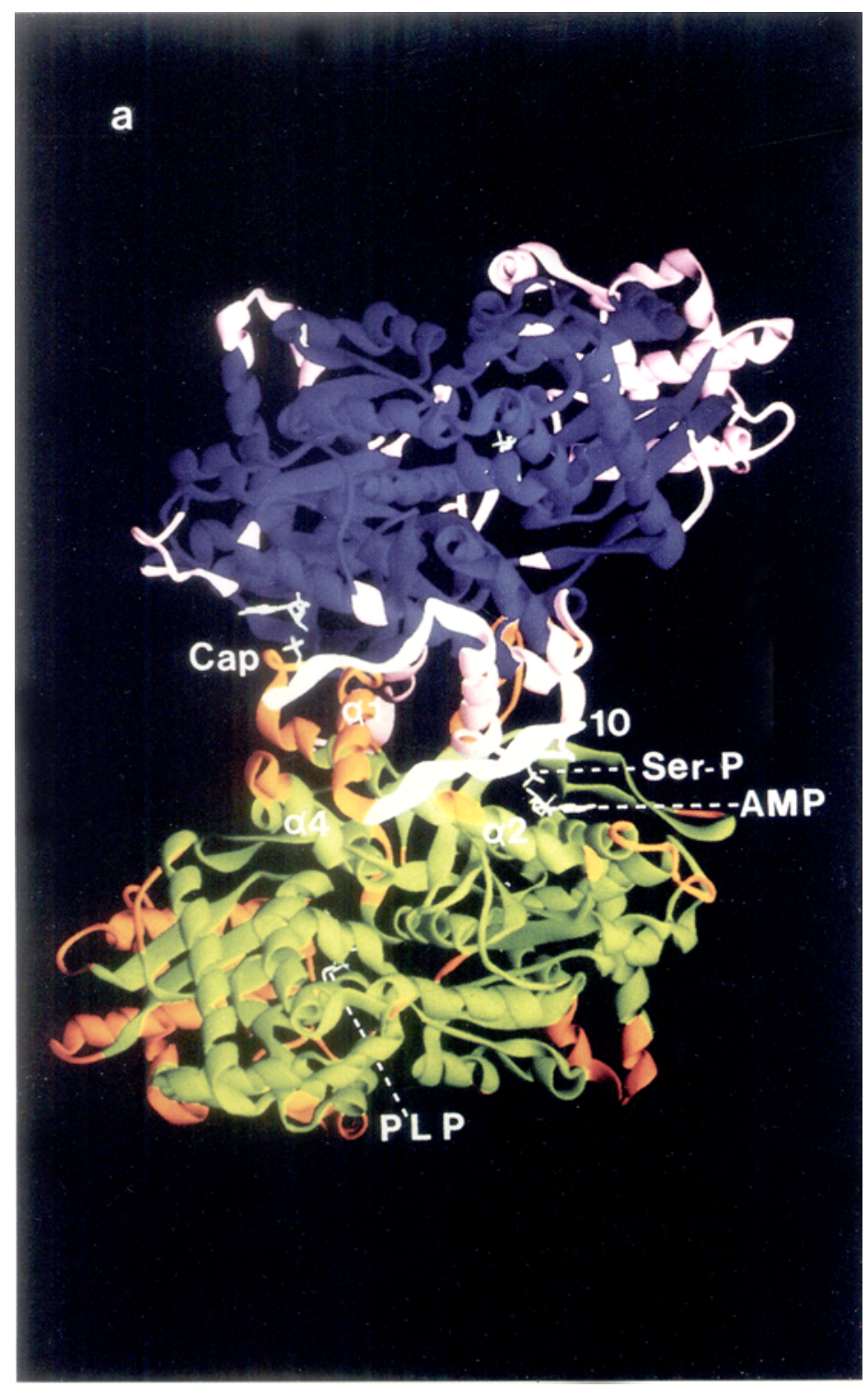

Fig. 12a

Figure 12. The dimers of $\mathbf{R}$ state phosphorylase $a$ (Figs. a, c, and e) and T state phosphorylase $b$ (Figs. $\mathrm{b}$, d, and f). Colour code: $R$ state (Figs. a, c, and e) subunit 1 green and subunit 2 blue with regions that differ by more than $1 \AA$ in $\mathrm{C} \alpha$ positions between $\mathrm{R}$ and $\mathrm{T}$ state tertiary structures shown in orange and pink for subunits 1 and 2 , respectively; T state (Figs. b, d, and f) subunit 1 cyan and subunit 2 purple with regions that differ more than $1 \AA$ in $C \alpha$ positions between $\mathrm{R}$ and $\mathrm{T}$ states shown in red and yellow. The $\mathrm{N}$-terminal residues (10-23) and the $\mathrm{C}$-terminal residues (837-842) are shown in white. Ligands: pyridoxal phosphate and sulphate ( $R$ state) and glucose-1-P (T state) are shown at the catalytic site; AMP at the allosteric effector site; Ser-P at Ser14 (R state GPa only); AMP at the nucleoside inhibitor site ( $T$ state only); and maltopentose at the glycogen storage site ( $T$ state only). a) and b): View down the 2-fold axis of the dimer with the allosteric sites and Ser-P sites towards the viewer. The catalytic site is at the rear. The view shows the change in conformation of the $\mathrm{N}$-terminal tail from intra to (continued on page 218) 


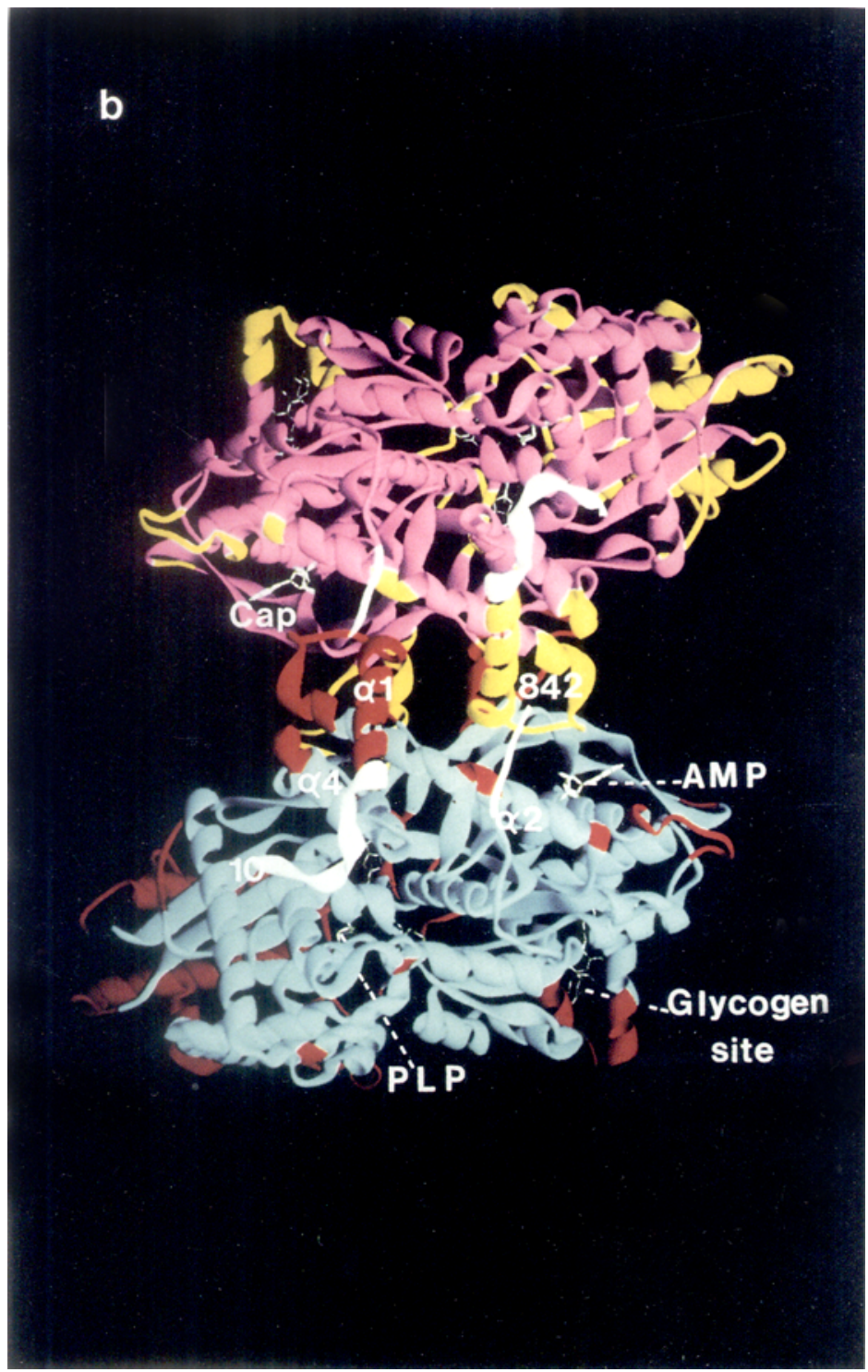

Fig. 12b

inter subunit contacts and the shifts of the $\alpha 1$ helix-cap- $\alpha 2$ helix and $\alpha 4-\alpha 5$ inter-helix loop.c) and d): View down the 2-fold axis of the dimer with the catalytic site and tower helices towards the viewer. The allosteric site is at the rear. The view illustrates the changes in the tower helices and the $280 \mathrm{~s}$ loop. The movements in the helix bundle (lower right; orange and red in $\mathbf{R}$ and $\mathrm{T}$ states) are part of the dimer-dimer contact in the tetramer in which these helices pack against part of the glycogen storage site (left). e) and f); View normal to the 2-fold axis of the dimer. The view shows the change in quarternary structure in which one subunit (subunit 2 ; top) rotates $10^{\circ}$ with respect to the other subunit (subunit 1 ; bottom) about an axis normal to the 2-fold axis that intercepts the axis at a point near the cap' $/ \alpha 2$ interface. The view shows changes at the subunit-subunit interface and the shifts of the $\mathrm{N}$-terminal and $\mathrm{C}$-terminal residues (from ref. 6). Ribbon diagram by Carson and BugG, 1986 (11). 


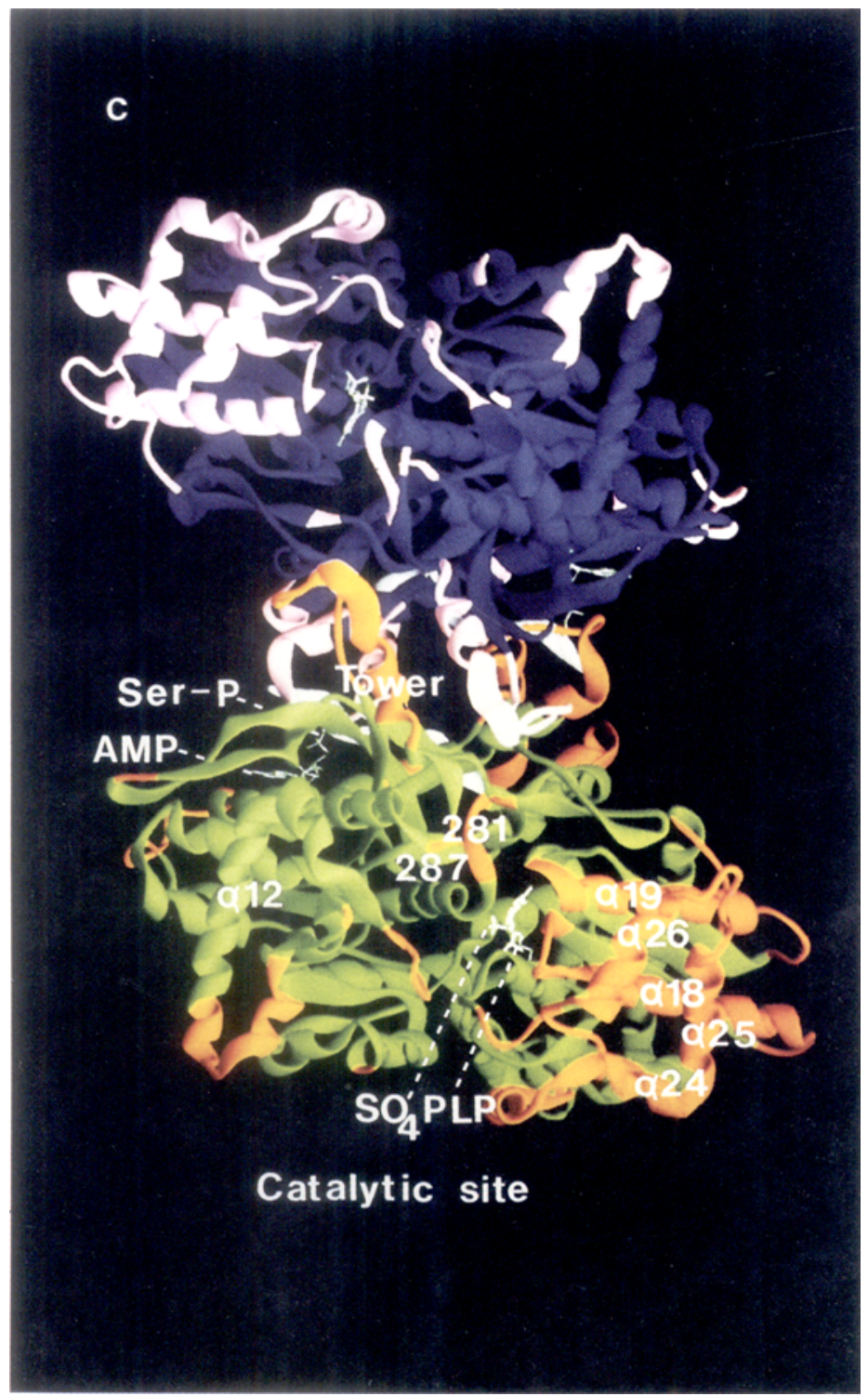

Fig. 12c

represented by the $\mathrm{N}$-terminal residues, the helices $\alpha 1$ ', $\alpha 2$ ', $\alpha 4$ and cap' of one subunit and $\alpha 2$ helix of the opposite subunit. The quaternary conformational change also affects the relative disposition of the tower helices, transmitting a signal to the catalytic site (5). The rms difference in $\mathrm{C} \alpha$ coordinates between one subunit of $\mathrm{T}$ phosphorylase $b$ and $\mathrm{R}$ phosphorylase $a$ is 1.3 $\AA$ (excluding residues 10-21) indicating the relatively small differences in tertiary structure which are localised (mostly) to the subunit in- terfaces and the catalytic site. In contrast, the quaternary changes result in an rms difference in Ca coordinates of the dimer of $6 \AA$, reflecting the large changes produced by the relative movement of the subunit with respect to each other (6).

\section{Activation by phosphorylation:}

Comparison of phosphorylases $a$ and $b(6,71)$ shows that the major relocation produced by phosphorylation involves the $\mathrm{N}$-terminal tail re- 


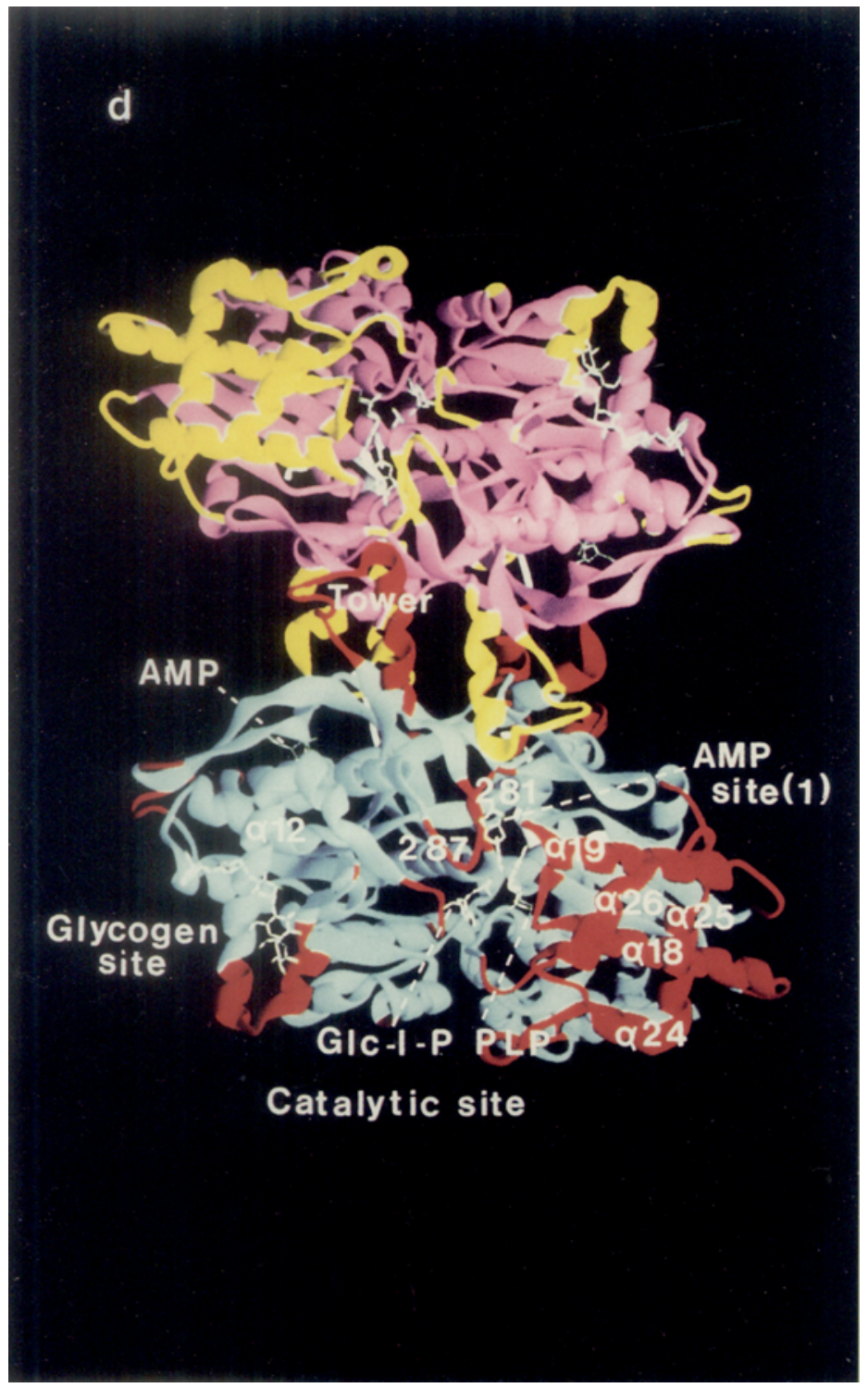

Fig. 12d

sidues 10-21. In phosphorylase $b$ these residues are poorly ordered but they have been located (50) in an extended conformation that places Ser-14 close to Glu501 on the helix $\alpha 16$. On phosphorylation the $\mathrm{N}$-terminal residues fold up into an irregular $3_{10}$ helix and the Ser-P makes contact to 2 arginine residues at the subunit interface, Arg69 from its own subunit and Arg43' from the other subunit (Figs. 12a and b). These interactions are made possible by the quaternary changes that result in the movement of the $\alpha 2$ helix (that contains Arg69) relative to the cap' (that contains Arg43') and substantial conformational changes in these residues (Fig. 13). Arg10 shifts $50 \AA$ from T state to R state reflecting the dramatic restructuring of the $\mathrm{N}$-terminal peptide on phosphorylation. In T state phosphorylase $b$ there are 11 acidic and 7 basic residues within $15 \AA$ of the $\mathrm{Ca}$ atom of Ser 14 (excluding residues $10-20$ ). This location of the tail provides a complimentary electrostatic environment to the basic $\mathrm{N}$-terminal tail and one which is inhos- 


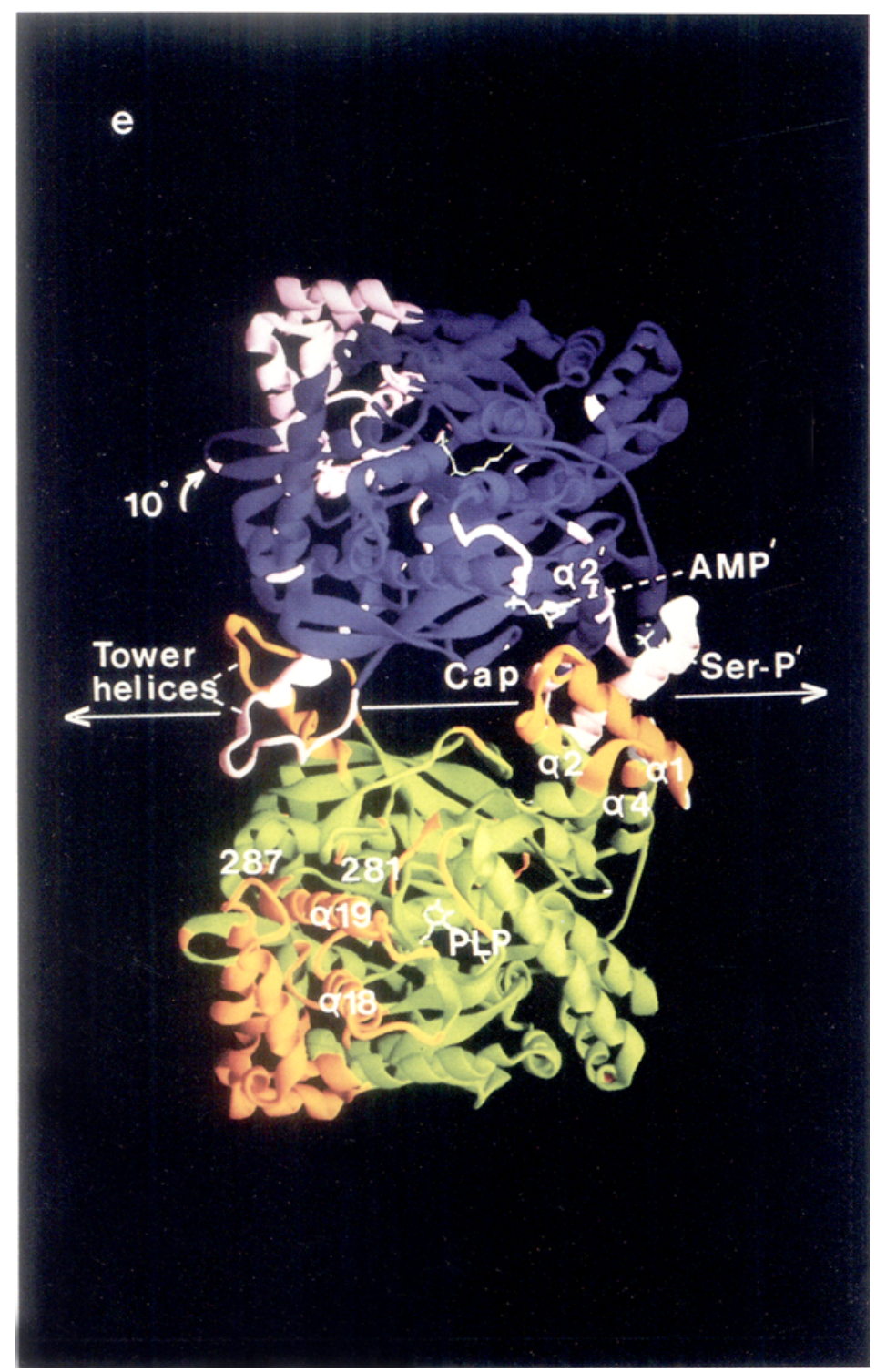

Fig. 12e

pitable to addition of a negatively charged phosphate. In R state phosphorylase $a$ there are 6 acidic and 11 basic residues in the vicinity of Ser-14 and the conformational change resulting from phosphorylation provides now a stabilising environment for the phosphate.

\section{Activation by AMP:}

The AMP allosteric site is located on the opposite side of the $\alpha 2$ helix to the Ser-P. The T to
$\mathrm{R}$ transition results in changes of the cap' residues especially Asp42' and Asn44' that flank Arg43', and to changes of the cap' with respect to the $\alpha 2$ helix that lead to a high affinity site in the $\mathrm{R}$ state. The crystallographic study of the binding of AMP to T state phosphorylase (6) showed that the major interactions of the nucleotide with the enzyme were through the phosphate group of the nucleotide to Arg309 and Arg310 on the $\alpha 8$ helix (Fig. 14). The base position was stabilised by long van den Waals inter- 


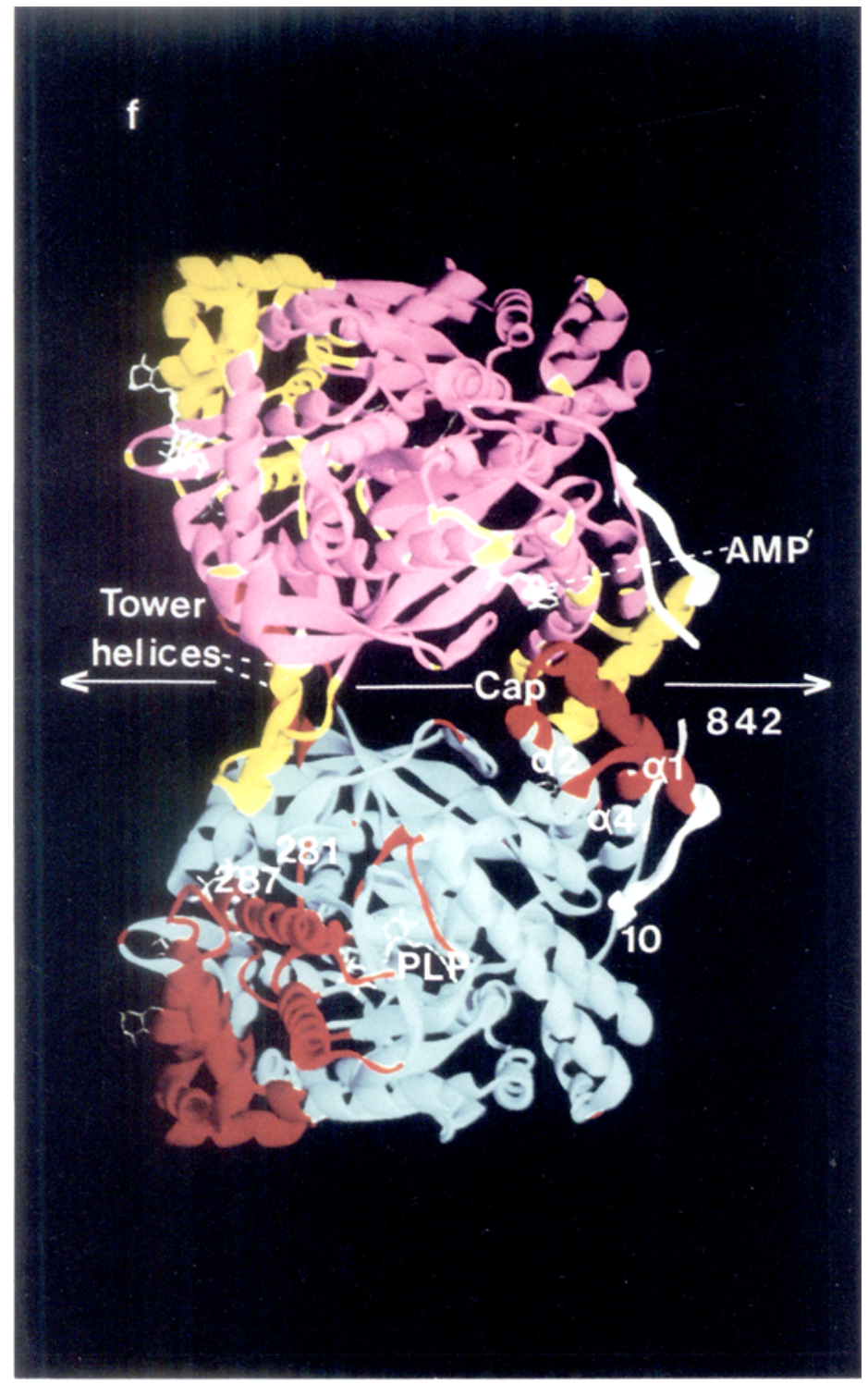

Fig. 12f

actions between the adenine and Tyr 75 and Val45' and residues of the cap were too far to make significant interactions. The open site correlates with the relatively low affinity displayed by $T$ state phosphorylase for AMP ( $K_{D}$ approx. 250-700 $\mu \mathrm{M}(51,59))$. The quaternary and tertiary changes on the $T$ to $R$ transition create a site that exhibits a 100 fold increase in affinity $\left(K_{D}=\right.$ $3 \mu \mathrm{M})(9)$. In the R state (6) the phosphate of the nucleotide makes similar contacts to Arg309 and $\mathrm{Arg} 310$ but these ionic links are augmented by a closer contact with Arg242. The most dramatic changes come from shifts in the cap residues that now allow direct hydrogen bonds between the $\mathrm{O} 2$ hydroxyl of the ribose and Asp42' and the N1 of the adenine and Asn44' (Fig. 14). There are improved van der Waals contact between the nucleotide and residues Tyr $75, \mathrm{Gln} 72$ and Val45'. The differences can be summarised by noting that there are 4 additional hydrogen bonds made in the $\mathrm{R}$ state to AMP compared to the T state and that the nucleotide is some $93 \%$ 

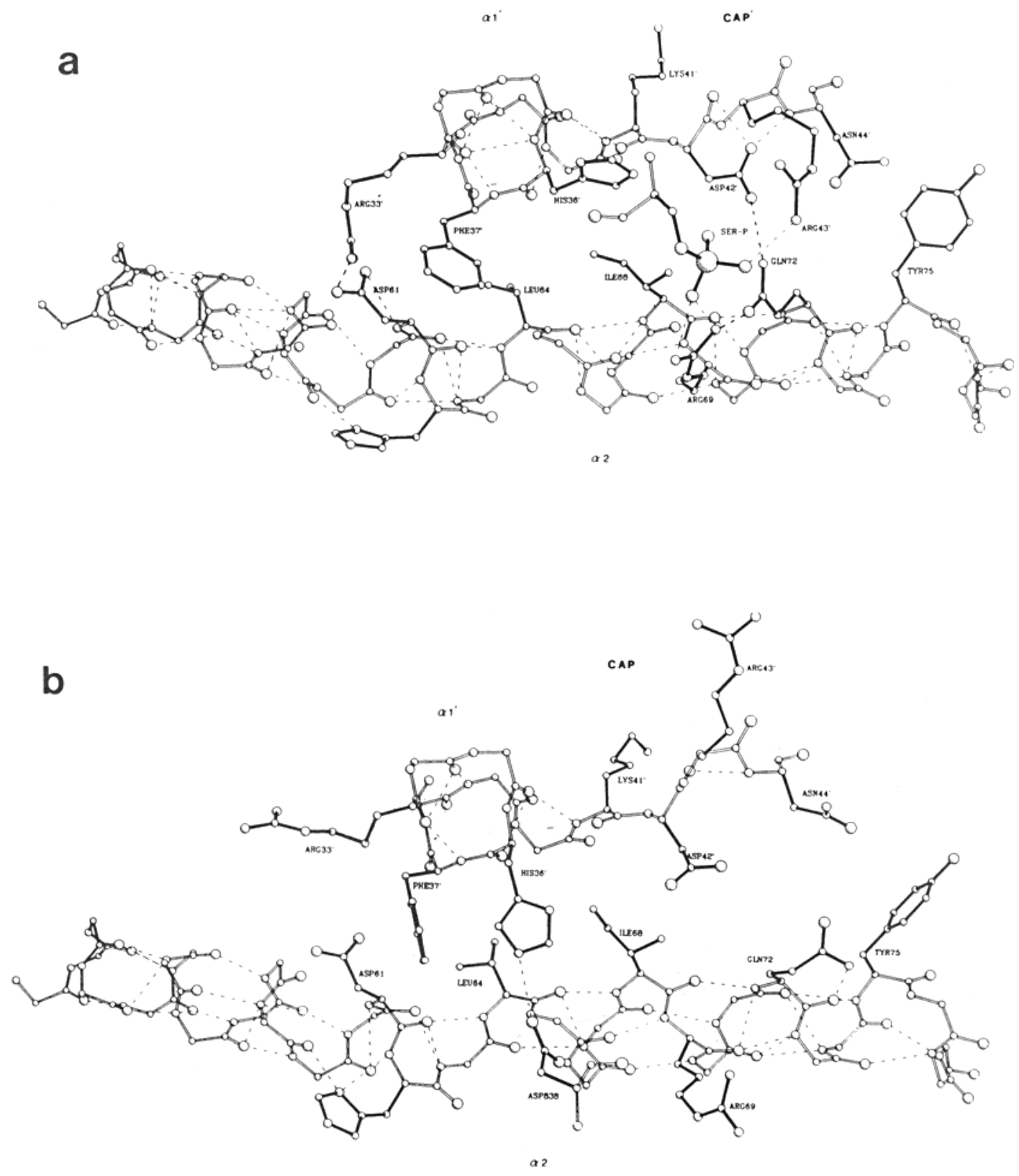

Figure 13. Comparison of the cap' $/ \alpha 2$ interactions at the subunit-subunit interface of a) phosphorylase $a$ and b) phosphorylase $b$. The view is down the 2 -fold axis of the dimer. In Figure 13a the Ser-P contacts Arg69 (from $\alpha 2$ helix) and Arg43' (from cap' of the other subunit) and the contacts are made possible by tertiary and quarternary structural changes on the T to $\mathrm{R}$ transition. Val15 docks against Ile68 (not shown) and there is a hydrogen bond from Asp42 to GIn72. In Figure 13b His36' from cap' is in ionic contact with Asp838 from the C-terminal region and adopts a different conformation (6). 


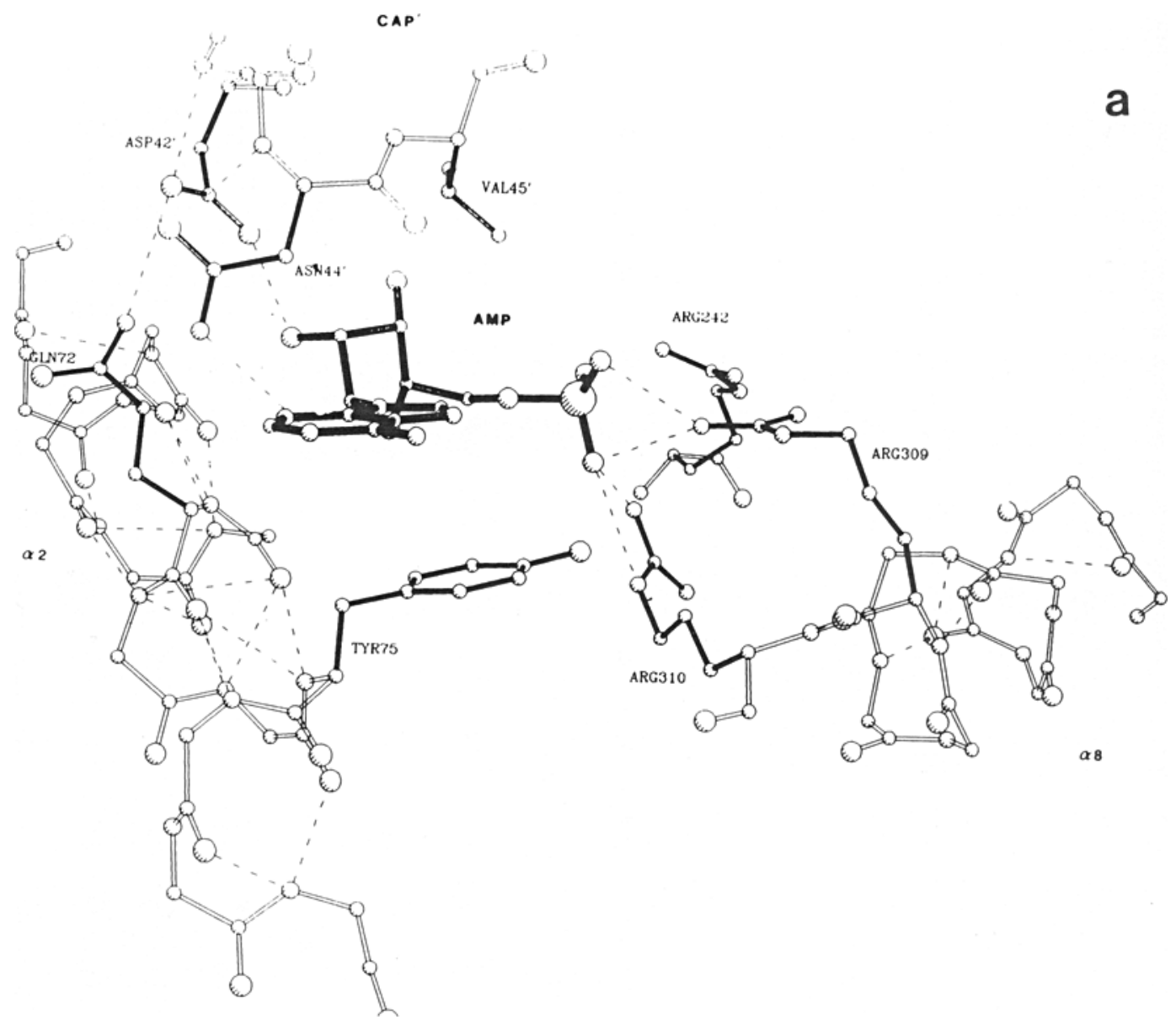

Figure 14. Comparison of AMP binding to a) R state phosphorylase $b$ and b) T state phosphorylase $b$. In the T state the site is more open and there are few contacts between the enzyme and AMP. In the T to R conversion the AMP shifts further into the site and the site is closed by movements of the cap' relative to the $\alpha 2$ helix (6).

buried in the $\mathrm{R}$ state compared to $66 \%$ buried in the T state.

\section{Communication to the catalytic site:}

The changes at the allosteric site and Ser-P site are communicated to the catalytic site through linked quaternary and localised structural changes that are focussed around the other major subunit interface. In the $\mathrm{T}$ state the tower helices of the 2 subunits are arranged in antiparallel constellation with close contacts between Asn270 and Asn274 and their symmetry related counterparts at the centre of these helices. On the $\mathrm{T}$ to $\mathrm{R}$ transition the tower helices are pulled apart by 2 turns of helix and the angle of tilt is changed to $-70^{\circ}$ (Figs. $12 \mathrm{c}-\mathrm{f}$ ). This dramatic change is communicated to the catalytic site through the 280s loop and indirect contacts to Arg569. The tower helices are anchored at their base by a short parallel $\beta$ sheet between residues 276-279 and 162-164. From here the chain leads to the loop 281-287 (280s loop) that forms the gate to the catalytic site. A change in the twist of this sheet which appears to be a consequence of the change in the tower helices perturbs resi- 


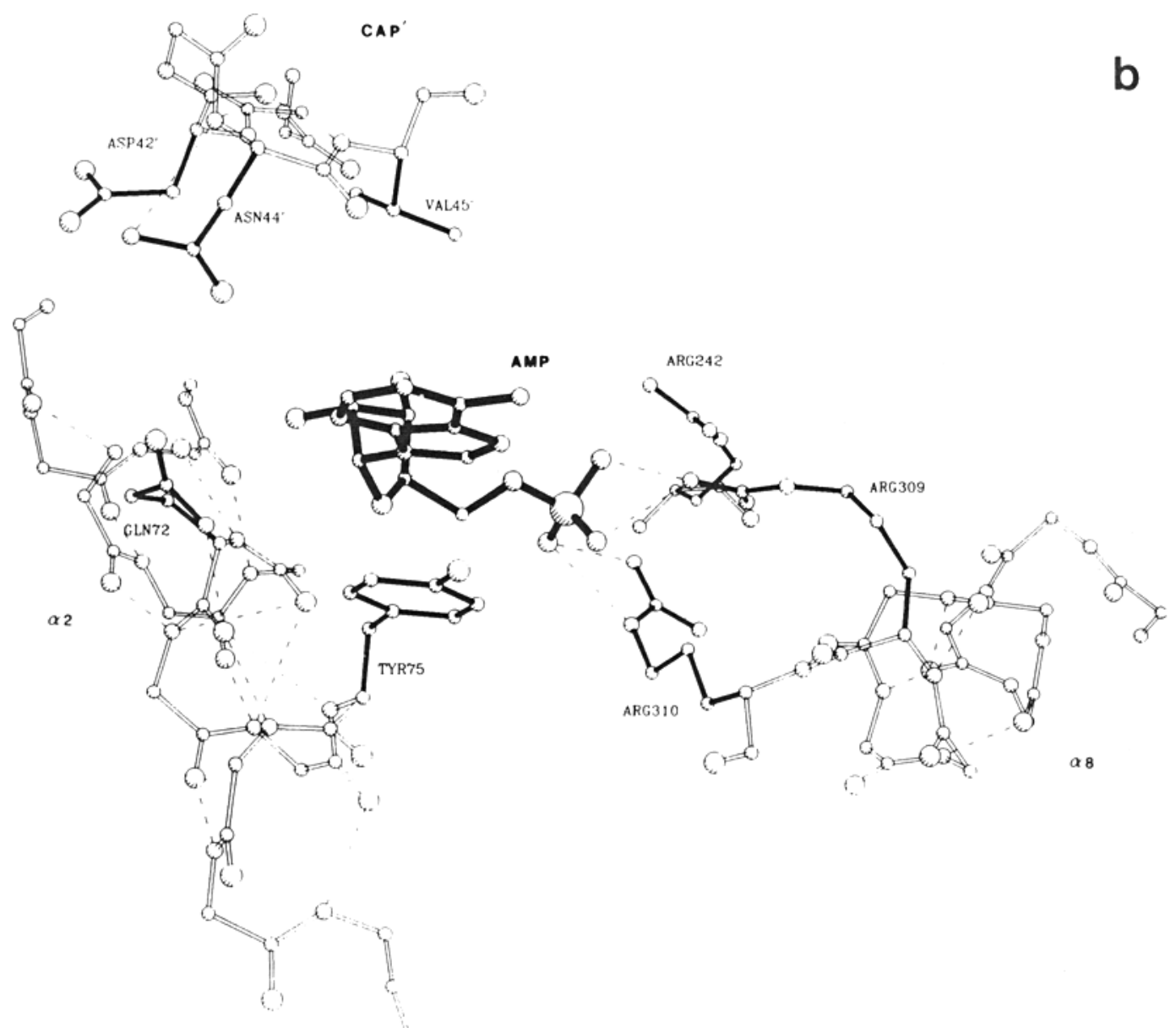

dues that are in contact with Arg569. In the R state residues 282 to 286 are disordered allowing access to the catalytic site and Arg569 swings down to a conformation similar to that observed in the heptulose-2-phosphate complex, and contacts the sulphate molecule that is bound at the catalytic site in the crystal. The sulphate is directly hydrogen bonded to the pyridoxal phosphate 5'-phosphate group and its position is similar to that observed for the phosphate peak in the putative attacking position seen in the time resolved studies (Fig. 6b). The alternative packing adopted by the tower helices provides a particularly suitable method by which tertiary and quaternary structural changes may be linked. The geometry of one helix is constrained by the other helix so that molecular symmetry is conserved and a concerted transition occurs.
Discussion of allosteric mechanism:

Comparison of the allosteric mechanism of phosphorylase with 3 other allosteric proteins whose structures are known from X-ray evidence has shown the common feature of linked tertiary and quaternary structural changes but the changes involve diverse intersubunit interactions and diverse mechanisms for communication between sites $(32,64)$. In glycogen phosphorylase changes at the subunit interface are consistent with both the model proposed by Monod, Wymann and Changeux (58), (MWC), and that proposed by Koshland, Nemethy and Filmer (44), (KNF), for enzyme cooperativity and regulation. In both models, the subunit interface forms the focus for transmission of information. The crucial difference between the 2 models is the strength of the constraints at the 
subunit interface. In the MWC model, effects are modulated by an equilibrium between 2 (or at least 2) symmetrical conformational states that differ in their affinity for ligands. A change in tertiary structure of one subunit must be accompanied by an equivalent change in the other subunits, facilitated by a quaternary conformational change, in order to conserve symmetry. In the KNF model it was proposed that an induced tertiary conformational response to ligand binding in one subunit leads to changes in the energy of the subunit-subunit interactions that may or may not make it easier for the other subunit to respond. A sequential conformational change of subunits is envisaged in which the oligomeric assembly need not be symmetrical.

Knowledge of the $\mathrm{R}$ and $\mathrm{T}$ state structures of the phosphorylase reveals nothing concerning the transient structural events occurring during the $\mathrm{T}$ to $\mathrm{R}$ transition and does not allow us to unequivocally distinguish between these 2 models. However, certain predictions regarding the transition can be made. A complete conversion to the $\mathrm{R}$-state structure at one effector site at the subunit interface independent of the other allosteric site and independent of a quaternary conformational change would lead to steric conflict (6). In particular constraints on the geometry of the tower helix prevent formation of intermediate structures, ensuring that tertiary structural change of the tower is strictly coupled to the quaternary conformational change. Likewise the creation of the high affinity AMP site that is formed at the cap'/ $\alpha 2$ interface on the $\mathrm{T}$ to $\mathrm{R}$ transition can only be achieved through symmetric conformational changes that affect both subunits.

Control by phosphorylation is now recognised as a ubiquitous control process by which intracellular events can be coupled to extracellular agents such as hormones and growth signals. Glycogen phosphorylase is the first phospho-regulated protein whose structure is known. The structural mechanism of activation by phosphorylation in phosphorylase is similar to that of allosteric regulation by effectors in which the phosphorylated $\mathrm{N}$-terminal tail acts as an allosteric effector through binding to its recognition site and favouring changes in conformational state of the enzyme that affect sites remote from the phosphorylation site. It is likely that other mechanisms will be discovered by which phosphorylation regulates protein activity. Indeed, in isocitrate dehydrogenase inactivation by phosphorylation appears to be achieved by electrostatic repulsion of the substrate (31). The structural studies with phosphorylase have shown how seemingly small modifications to the protein can lead to changes in structure such that binding sites can exhibit at least a 100 fold difference in affinity and allow the enzyme's activity to be coordinated with metabolic requirements of the cell.

\section{ACKNOWLEDGEMENTS}

I wish to thank my collaborators without whom none of this work would have been possible. In particular Dr. K.R. ACHARYA and Dr. D.I. STUART who were responsible for skill and originality in data collection and high resolution refinement of the $T$ state structure and in ligand binding studies; Dr. P.J. McLaughuin who first analysed the formation of heptulose-2-phosphate and the oligosaccharide binding; Dr. J. HAJDU who led the time resolved studies and the Laue diffraction analysis; Dr. N.G. Oıкonomakos for work on the pyridoxal phosphate and other ligand binding studies and correlation of crystallographic and kinetic properties; Dr. D. BARForD outstanding work on $\mathrm{R}$ state phosphorylase that led an understanding of the allosteric mechanism; Dr. J. MARTIN who in a ligand binding study first located the N-terminal tail in phosphorylase $b$; Miss S.-H. Hu for work with R state phosphorylase $a$ and ligand binding studies. In addition I am grateful to Dr. G.L. TAYLOR for management of the computer resources at the Laboratory of Molecular Biophysics and to the staff at the SERC's Synchrotron Radiation Source, Daresbury for the synchrotron facilities. Over the years we have enjoyed fruitful collaboration with Professor E.J.M. Helmreich, Dr. D. Palm and Dr. H. KLEIN at Wutzberg and with Professor R.J. Fletterick, Professor S.R. Sprang and Dr. E. Goldsmith at San Francisco and Dallas. This work has been supported by the MRC and the SERC. Finally, it is a pleasure to acknowledge the inspiration and encouragement of Sir DAVID PHILlips throughout nearly 18 years of phosphorylase crystallography. 


\section{REFERENCES}

1. Acharya, K.R., D.I. Stuart, K.M. Varvill \& L.N. Johnson: Glycogen Phosphorylase $b$ : description of the protein structure. World Scientific Publishers. In press (1990)

2. ArIKI, M. \& T. Fukus: Affinity of glucose analogues for $\alpha$-glucan phosphorylases from rabbit muscle and potato tubers. J. Biochem. 81, 1017. 1024 (1977)

3. Arndt, U.W. \& A.J. Wonacotr: The Rotation Method in Crystallography, North Holland, Amsterdam (1977)

4. Baranowski, T., B. Illingworth, D.H. Brown \& C.F. CorI: The isolation of 5'-pyridoxal phosphate from crystalline muscle phosphorylase. Biochim. Biophys. Acta 25, 16-21 (1957)

5. BARFORD, D. \& L.N. JoHnson: The allosteric transition of glycogen phosphorylase. Nature 340,609 $616(1989)$

6. Barford, D., S.-H. Hu \& L.N. Johnson: The structural mechanism for glycogen phosphorylase control by phosphorylation and AMP. submitted (1990)

7. BLACK, W.J. \& J.H. WANG: Studies on the allosteric activation of glycogen phosphorylase $b$ by nucleotides. J. Biol. Chem. 243, 5892-5898 (1968)

8. Brunger, A.T., J. Kuruyan \& M. Karplus: Crystallographic $\mathrm{R}$ factor refinement by molecular dynamics. Science 235, 458-460 (1987)

9. Buc, $\mathbf{H}$.: On the allosteric interaction between 5'AMP and orthophosphate in glycogen phosphorylase b. Biochem. Biophys. Res. Commun. 28, 5964 (1967)

10. Campbell, J.W., I.J. Clifton, T.J. Greenough, J. Hajdu, S.C. Harrison, R.C. Liddington \& A.K. Shrive: Calcium binding sites in Tomato Bushy Stunt Virus visualised by Laue crystallography. J. Mol. Biol. 214, 627-632 (1990)

11. CARson, M. \& C.E. Bugg: A ribbon programme for display of protein structures. J. Mol. Graphics 4, 121-122 (1986)

12. Cori, G.T., S.P. Colowich \& C.F. Cori: The formation of glucose-1-phosphoric acid in extracts of mammalian tissues of yeast. J. Biol. Chem. 123 , 381-389 (1938)

13. Cruichshanx, D.W.J., J.R. Helliwell \& K. Moffat: Multiplicity distribution of reflections in Laue diffraction. Acta Cryst. A43, 656-674 (1987)

14. Dreyfus, M., B. Vandengunder \& H. Buc: Mechanism of allosteric activation of glycogen phosphorylase probed by the reactivity of essential arginyl residues. Biochemistry 20, 1748-1756 (1980)

15. Engers, H.D. \& N.B. Madsen: The effects of anions on the activity of phosphorylase $b$. Biochem. Biophys. Res. Commun. 97, 513-519 (1968)
16. Farber, G.K., P.A. Machin, S.C. Almo, G.A. Petsko \& J. HAJDU: X-ray Laue diffraction from crystals of xylose isomerase. Proc. Natl. Acad. Sci. USA 85, $112-115$ (1988)

17. Frlodan, K. \& W.E. Hull: ${ }^{31} \mathrm{P}$ nuclear magnetic resonance studies of glycogen phosphorylase from rabbit muscle: ionisation states of pyridoxal phosphate. Proc. Natl. Acad. Sci. USA 74, 856-860 (1977)

18. Fletterick, R. \& S.R. Sprang: Glycogen phosphorylase structure and function. Accounts of Chemical Research 15, 361-369 (1982)

19. Friederich, W., P. Knipping \& M. Von Laue: Sitzungsberichte der Math. Phys. Klasse, (Kgl.) Bayerische Akademie der Wissenschaften, Munchen, 303-322 (1912)

20. Graves, D.J. \& J.H. WANG: $\alpha$-glucan phosphorylases - chemical and physical basis of catalysis and regulation. In: The Enzymes (P.D. Boyer ed.) 3rd edit. Vol. 7, pp. 435-482, Academic Press, New York (1972)

21. Hajdu, J. \& L.N. Johnson: Progress with Laue diffraction studies on protein and virus crystals. Biochemistry 29, 1669-1678 (1990)

22. Hajdu, J., P.J. Mclaughlin, J.R. Helliwell, J. Shelden \& A.W. Thompson: A flow cell for prot tein crystallography. J. Appl. Cryst. 18, 528-532 (1986)

23. Hajdu, J., K.R. Acharya, D.I. Stuart, P.J. Mclaughlin, D. Barford, N.G. Oikonomakos, H.W. Kıetn \& L.N. Johnson: Catalysis in the crystal: synchrotron radiation studies with glycogen phosphorylase $b$. EMBO J. 6, 539-546 (1987)

24. Hajdu, J., P.A. Machin, J.W. Campbell, T.J. Greenhough, I.J. Clifton, S. Zurek, S. Gover, L.N. Johnson \& M. Elder: Millisecond X-ray diffraction and the first electron density map from Laue photographs of a protein crystal. Nature, Lond. 329, 115-116 (1987)

25. Hehre, E.J, C.F. Brewer, T. Uchiyama, P. Schles SELMAN \& J. LehMAN: Scope and mechanism of carbohydrase action. Stereo specific hydration of 2,6anhydro-1-deoxy-D-gluco-hept-1-enitol catalysed by $\alpha$ and $\beta$ glucosidases and an inverting exo- $\alpha$-glucanase. Biochemistry 19, 3557-3564 (1980)

26. Helliwelt, J.R.: The uses of synchrotron radiation in the crystallography of molecular biology. Rep. Prog. Phys. 47, 1403-1497 (1984)

27. Helliwel, J.R., T.J. Greenough, P.D. Carr, S.A. Rule, P.R. Moore, A.W. Thompson \& J.S. Worgan: A central data collection facility for protein crystallography, small angle diffraction and scattering with the Daresbury Laboratory synchrotron radiation source. England J. Phys. E 15. 13631372 (1982) 
28. Hell.iweli, J.R., M.Z. Paplz, I.D. Glover, J. Habash, A.W. Thompson, P.R. Moore, N. Harris, D. Croft \& E. Pantos: The wiggler protein crystallography work station at the Daresbury synchrotron radiation source: progress and results. Nuclear Instrum. Methods Phys. Res. A246, 617 623 (1986)

29. Helliwell, J.R., J. Habash, D.W.J. Cruickshank, M.M. Harding, T.J. Greenough, J.W. Campbell, I.J. Clifton, M. Elder, P.A. Machin, M.Z. Paplz \& $S$. Zurek: The recording and analysis of synchrotron X-radiation Laue diffraction photographs. J. Appl. Cryst. 22, 483-497 (1989)

30. Helmreich, E. \& C.F. Cori: The role of adenylic acid in the activity of glycogen phosphorylase. Proc. Natl. Acad. Sci. USA 51, 131-138 (1964)

31. Hurley, J.H., A.M. Dean, J.L. Sohl, D.E. Koshland \& R.M. Stroud: Regulation of an enzyme by phosphorylation at the active site. Science 249, 1012-1016 (1990)

32. Johnson, L.N. \& D. Barford: Glycogen phosphorylase: The structural basis of the allosteric response and comparison with other allosteric proteins. J. Biol. Chem. 265, 2409-2412 (1990)

33. Johnson, L.N. \& J. Hajdu: Synchrotron studies on enzyme catalysis in crystals. In: Biophysics and Synchrotron Radiation (S. Hasnain ed.) Ellis Horwood, Chichester pp. 142-155 (1989)

34. Johnson, L.N., J. Cheetham, P.J. Mclaughlin, K.R. Acharya, D. Barford \& D.C. Phillips: Protein oligosaccharide interactions. Current Topics in Microbiol. and Immunol. 139, 81-134 (1988)

35. Johnson, L.N., J. Hajdu, K.R. Acharya, D.I. Stuart, P.J. Mclaughlin, N.G. Oikonomakos \& D. BARFORD: Glycogen phosphorylase $b$. In: Allosteric Enzymes 81-127 (G. Herve ed.) CRC Press, Baca Raton, Florida (1989)

36. Johnson, L.N., K.R. Acharya, M.D. Jordan \& P.J. McLaughlin: The refined crystal structure of the phosphorylase-heptulose 2-phosphate-oligosaccharide-AMP complex. J. Mol. Biol. 211, 645-661 (1990)

37. Kaplan, J.H., B. Forbush \& J.F. Hoffman: Rapid photolytic release of adenosine 5'triphosphate analogue: utilisation by the $\mathrm{Na}: \mathrm{K}$ pump of human red blood cell ghosts. Biochemistry 17 . 1929-1935 (1978)

38. Kasvinsky, P.J. \& N.B. Madsen: Activity of glycogen phosphorylase in the crystalline state. J. Biol. Chem. 251, 6852-6859 (1976)

39. Kasvinsky, P.J., N.B. Madsen, R.J. Fletterick \& J. SygusCH: X-ray crystallographic and kinetic studies of oligosaccharide binding to phosphorylase. J. Biol. Chem. 253, 1290-1296 (1978)

40. Kasvinsky, P.J., N.B. Madsen, J. Sygusch \& R.J.
FLETTERICK: The regulation of glycogen phosphorylase $a$ by nucleotide derivatives. J. Biol. Chem. 253, 3343-3351 (1978)

41. Kasvinsky, P.J., S. Shechosky \& R.J. FletteRICK: Synergistic regulation of phosphorylase $a$ by glucose and caffeine. J. Biol. Chem. 253, 9102-9106 (1978)

42. Klein, H.W., M.J. IM, D. Palm \& E.J.M. Helm. REICH: Does pyridoxal 5'-phosphate function in glycogen phosphorylase as an electrophile or as a general acid catalyst? Biochemistry 23, 5853-5861 (1984)

43. Klein, H.W., M.J. Im \& D. PaLm: Mechanism of phosphorylase reaction: utilisation of D-glucohept-1-enitol in the absence of primer. Eur. J. Biochem. 157, 107-114 (1986)

44. Koshl.and, D.E., G. Nemethy \& D. Filmer: Comparison of experimental binding data and theoretical models in proteins containing subunits. Biochemistry 5, 365-385 (1966)

45. KREBS, E.G. \& E.H. Fischer: The phosphorylase $b$ to $a$ converting enzyme of rabbit skeletal muscle. Biochim. Biophys. Acta 20, 150-157 (1956)

46. Leonidas, D.D., N.G. Oikonomakos, A.C. Papa georgion, A. Xenakis, C.T. Cazianis \& F. Bem: The ammonium sulphate activation of phosphorylase b. FEBS Lett. 261, 23-27 (1990)

47. MADSEN, N.B.: Glycogen phosphorylase: control by phosphorylation. In: The Enzymes (Boyer, P.D. \& Krebs, E.G., eds.) 3rd edit. vol. 17, pp. 366-394, Academic Press, New York (1986)

48. Madsen, N.B. \& S.G. Withers: Glycogen phosphorylase and derivatives. In: Coenzymes and Cofactors; Pyridoxal Phosphate and Derivatives (Dolphin, D., Paulson, R. \& Avramovic, O., eds.) pp. 1-29, Wiley, New York (1986)

49. MarTin, J.L.: Molecular interactions involving glycogen phosphorylase. D. Phil. Thesis, University of Oxford (1990)

50. Martin, J.L., L.N. Johnson \& S.G. Withers: Comparison of the binding of glucose and glucose-1phosphate derivatives to $\mathrm{T}$ state glyvogen phosphorylase $b$. Biochemistry. In press (1990)

51. Mateo, P.L., C. Baron, L.M. Obdullo, J.S. Jemenez \& M. Cortuo: AMP and IMP binding to glycogen phosphorylase b. J. Biol. Chem. 259, 9384-9389 (1984)

52. McCray, J.A. \& D.R. Trentham: Properties and uses of photoreactive caged compounds. Ann. Rev. Biophys. Biophys. Chem. 18, 239-270 (1989)

53. McLaughlin, P.J.: Crystallographic studies on glycogen phosphorylase $b$. D.Phil. Thesis, University of Oxford (1985)

54. Mclaughlin, P.J., D.I. Stuart, H.W. Klein, N.G. Oikonomakos \& L.N. Johnson: Substrate cofactor 
interactions for glycogen phosphorylase $b$. A binding study in the crystal of heptenitol and heptulose-2-phosphate. Biochemistry 23, 5862-5873 (1984)

55. Metzger, B.E., E. Helmreich \& L. Glaser: The mechanism of activation of skeletal muscle glycogen phosphorylase $a$ by glycogen. Proc. Natl. Acad. Sci. USA 51, 131-138 (1967)

56. Meyer, F., L.M.G. Heilmeyer, R.H. Hashie \& E.H. FISCHER: Control of phosphorylase in the glycogen particle. I. Isolation and characterisation of the protein glycogen complex. J. Biol. Chem. 245, 6642-6648 (1970)

57. Moffat, K., D.M.E. Szebeny \& D.H. Bllderback: $\mathrm{X}$-ray Laue diffraction from protein crystals. Science 223, 1423-1425 (1984)

58. Monod, J., J. Wyman \& J.-P. Changeux: On the nature of allosteric transitions: a possible model. $J$. Mol. Biol. 12, 88-118 (1965)

59. Motr, D.M. \& A.L. Bieber: Structural specificity of the adenosine 5'-phosphate site on glycogen phosphorylase b. J. Biol. Chem. 245, 4058-4066 (1970)

60. Newgard, C.B., P.K. Hwang \& R.J. Fletterick: The family of glycogen phosphorylases: structure and function. Crit. Rev. Biochem. Mol. Biol. 24, 69-99 (1989)

61. Oikonomakos, N.G., L.N. Johnson, K.R. Acharya, D.I. Stuart, D. Barford, J. HaJdu, K.M. VARVILl, A.E. Melpidou, T. Papgeorgiou, D.J. Graves \& D. PALM: The pyridoxal phosphate site in glycogen phosphorylase $b$. The structure in the native enzyme and in 3 derivatives. Biochemistry 26, 83818389 (1987)

62. Palm, D., H.W. Klein, R. Schinzel, M. Buehner \& E.J.M. Helmreich: The role of pyridoxal 5'-phosphate in glycogen phosphorylase catalysis. Biochemistry 29, 1099-1107 (1990)

63. Parrich, R.F., R.J. Uhing \& D.J. Graves: Effect of phosphate analogues on the activity of pyridoxal reconstituted glycogen phosphorylase. Biochemistry 16, 4824-4831 (1977)

64. Perutz, M.F.: Mechanisms of cooperativity and allosteric regulation in proteins. Quart. Rev. Biophys. 22, 139-237 (1989)

65. Philip, G., G. Gringel \& D. Palm: Rabbit muscle phosphorylase derivatives with oligosaccharides covalently bound to the glycogen storage site. Biochemistry 21, 3042-3050 (1982)

66. Praly, J.P. \& R.U. Lemieux: The influence of solvent on the magnitude of the anomeric effect. Can. J. Chem. 65, 213-223 (1987)
67. Schlichting, I., S.C. Almo, G. Rapp, K.S. Wilson, K. Petracos, A. Lentfer, A. Wittinghofer, W. Kabsch, E.F. Pai, G.A. Petsko \& R.S. Goody: Time resolved $\mathrm{X}$-ray crystallographic study of the conformational changes in Ha-Ras p21 protein on GTP hydrolysis. Nature 345, 309-315 (1990)

68. Shrive, A.K., I.J. Cl.fton, J. Hajdu \& T.J. Greenhough: Laue film integration and deconvolution of overlapping reflections. J. Appl. Cryst. $23,169-174(1990)$

69. Sotiroudis, T.G., N.G. Oikonomakos \& A.E. Evan. GELOPOuLos: Phosphorylase $b$ covalently bound to glycogen. Properties of the complex. Biochem. Biophys. Res. Commun. 90, 234-239 (1978)

70. Sprang, S.R. \& R.J. Fletterick: The structure of glycogen phosphorylase $a$ at $2.5 \AA$ resolution. J. Mol. Biol. 131, 523-551 (1979)

71. Sprang, S.R., K.R. Acharya, E.J. Goldsmith, D.I. Stuart, K. Varvill, R.J. Fletterick, N.B. Madsen \& L.N. Johnson: Protein phosphorylation: structural changes between glycogen phosphorylase $b$ and $a$. Nature 336, 215-221 (1988)

72. Titani, K., A. Koide, J. Hermann, L.H. Ericsson, S. Kumar, R.D. Wade, K.A. Walsh, H. Neurath \& E.H. Fischer: Complete amino acid sequence of rabbit muscle glycogen phosphorylase. Proc. Natl. Acad. Sci. USA 74, 4762-4766 (1977)

73. Vandenbunder, B. \& H. Buc: The reactivitity of arginine residues interacting with glucose-1-phosphate in glycogen phosphorylase. Eur. J. Biochem. $133,509-513$ (1983)

74. Wang, J.H., M. Shonka \& D.J. Graves: The effect of glucose on the sedimentation and catalytic activity of glycogen phosphorylase. Biochemistry 4 , 2296-2301 (1965)

75. Wansom, J.-C. \& P.J. Drockmans: Rabbit skeletal muscle glycogen. J. Cell Biol. 38, 130-150 (1968)

76. Weber, I.T., L.N. Johnson, K.S. Wilson, D.G.R. Yeates, D. Wild \& J.A. Jenkins: Crystallographic studies on the activity of glycogen phosphorylase b. Nature 274, 433-437 (1978)

77. Wierenga, R.K., M.C.H. Mayer \& W.J. Hol: Interaction of pyrophosphate moities with $\alpha$ helices in dinucleotide binding proteins. Biochemistry 24, 1346-1357 (1985)

78. Wyckoff, H.W., M. Doscher, D. Tsernoglou, T. Inagami, L.N. Johnson, K.D. Hardman, N.M. Alle. well, D.M. Kelly \& F.M. Richards: The design of a flow cell system for X-ray analysis of crystalline proteins and applications to crystal chemistry. J. Mol. Biol. 27, 563-578 (1967) 